
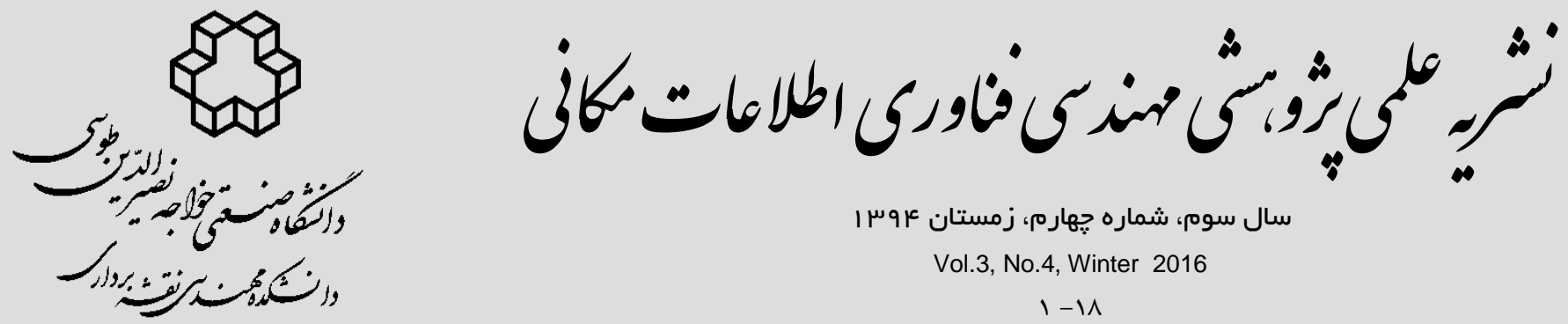

سال سوم، شماره جهارم، زمستان ع سرן Vol.3, No.4, Winter 2016

$1-11$

طبقهبندى تصاوير يلاريمترى رادار با روزنه مجازى بر اساس

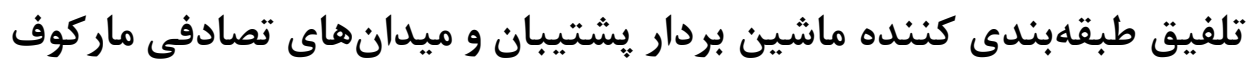

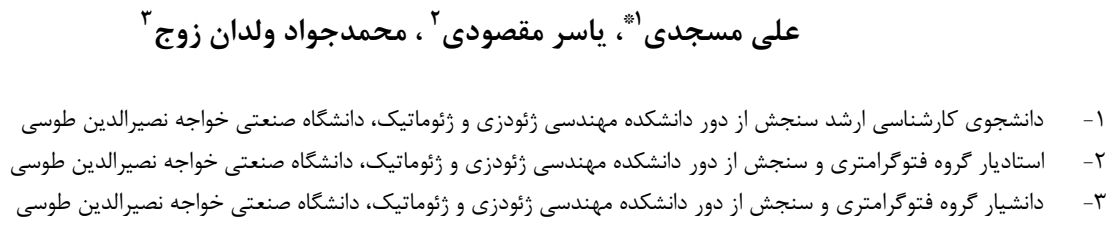

تاريخ دريافت مقاله: |r/r/F

جكيده

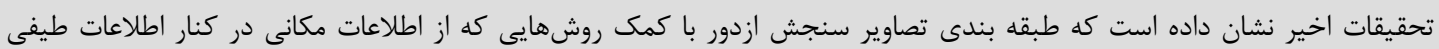

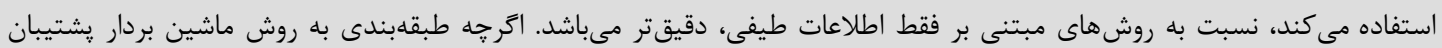

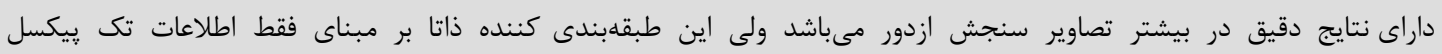

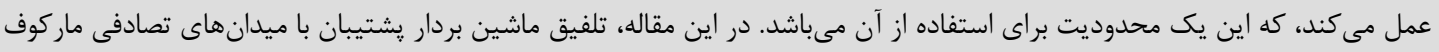

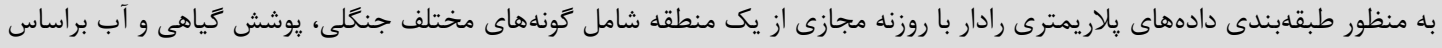

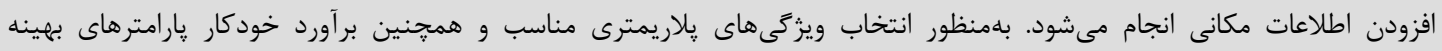

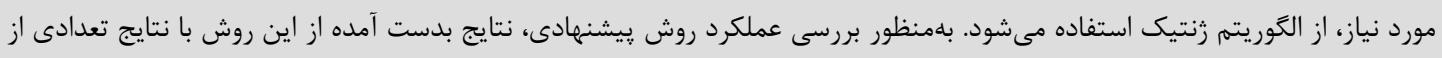

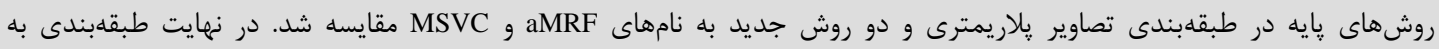

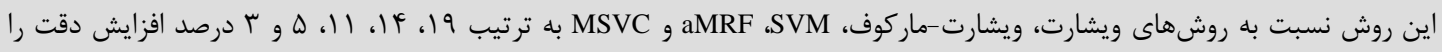
نشان مىدهد.

كليد وازهها : ميدان تصادفى ماركوف، ماشين بردار رشتيبان، طبقهبندى متنى تصاوير، اطلاعات مكانى، سنجش ازدور.

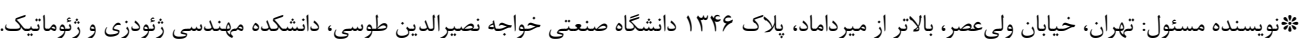




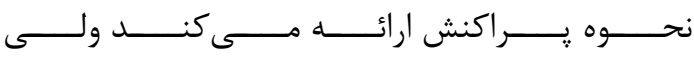

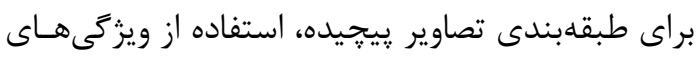

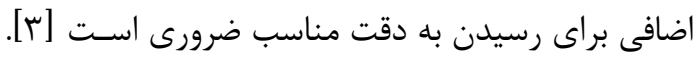

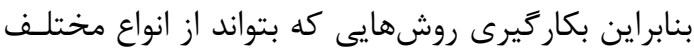

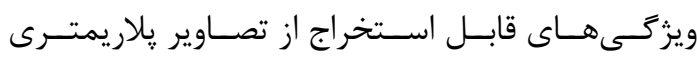

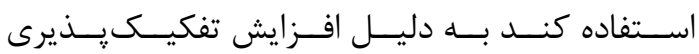
بين كلاسهاى مختلف كاملا منطقى به نظر مسىرسـد.

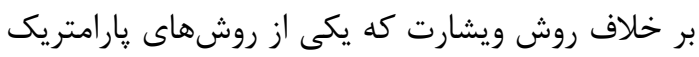

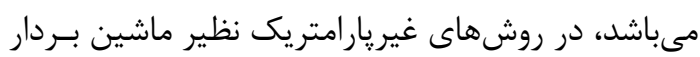

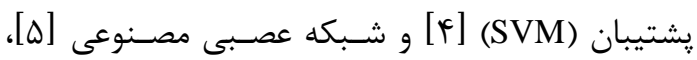

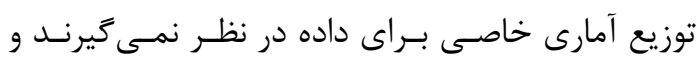

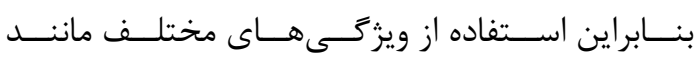

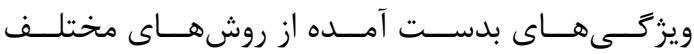

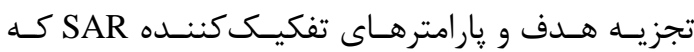
توزيع آمارى مشخصى ندارند نيز ممكن خواهد بوند بودين روش ماشين بردار يشتيبان يكى از روشهـاى مشههور

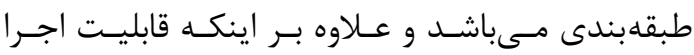

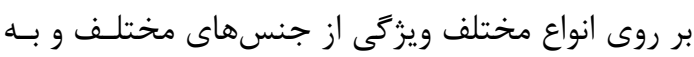

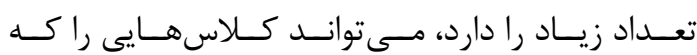

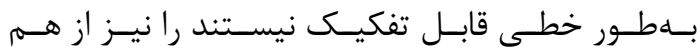

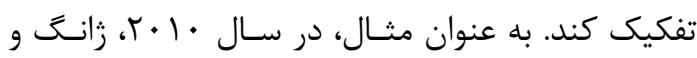

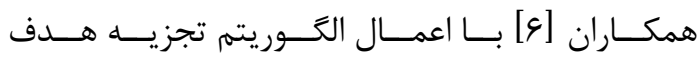
مدل يراكنش קند مولفهاى بر روى ماتريس كوواريانس

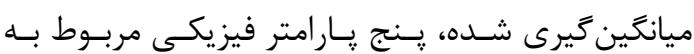

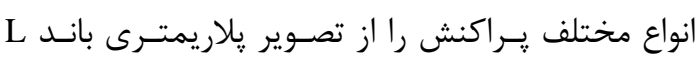

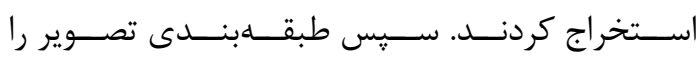

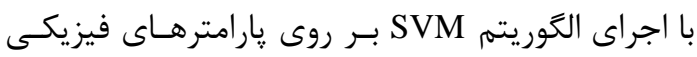

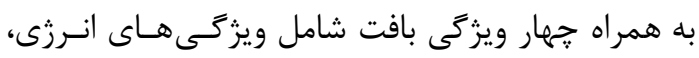

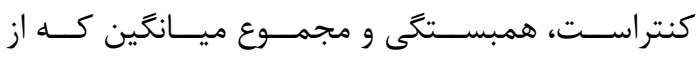
ماتريس همرخدادى استخراج شده بودند، انجـام دادنـد.

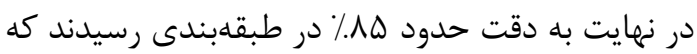

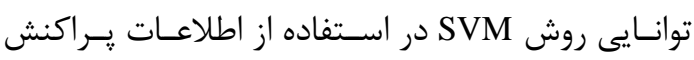
در كنار اطلاعات مكانى را نشان مىدهد.

طبقهبندى مناطق جنگلى به دليل اهميت اين مناطق و

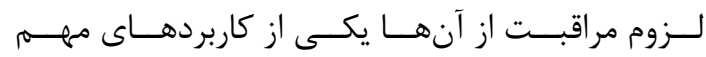

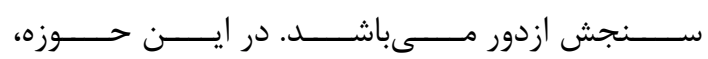
تصـاوير يلاريمتـــى رادار بــا روزنـهـه مجــازى (SAR)

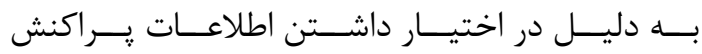

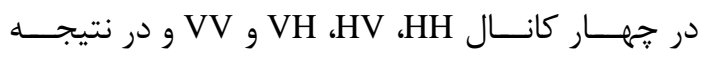

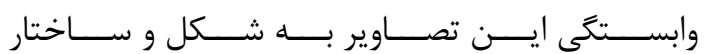
كونههاى جنكلى، داراى قابليتهاى زيـادى مسىباشــند.

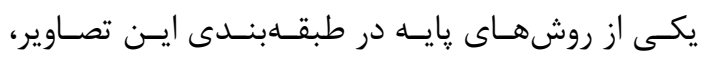

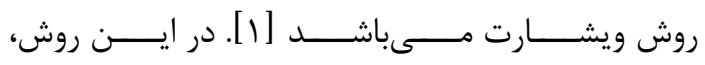

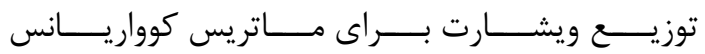
در نظر گرفته مىشود و شبيه به روش بيشينه شئه شباهت،

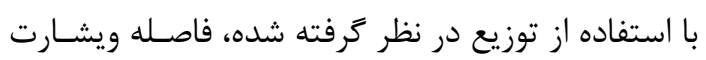

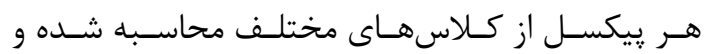
در نهايت طبقهبندى بر اساس اين فاصله انجام مىشود.

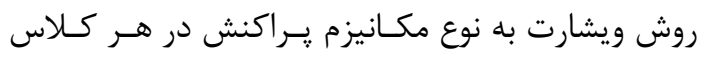

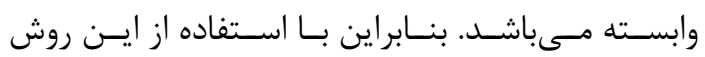

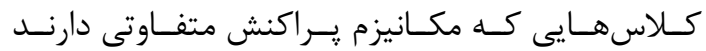

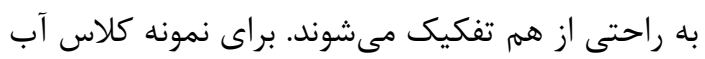

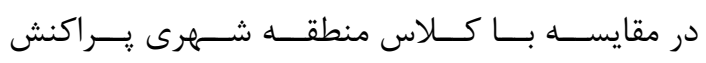

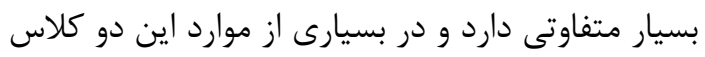

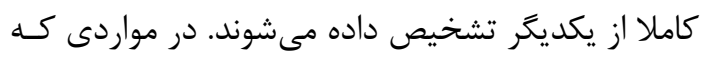

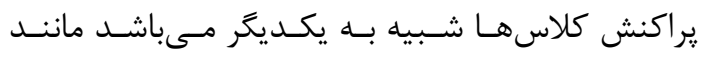

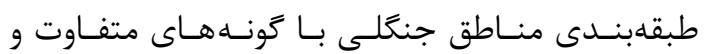

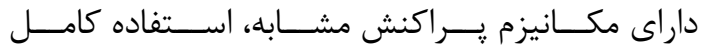

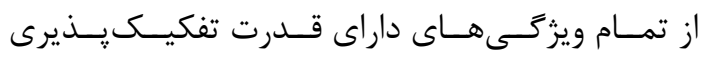

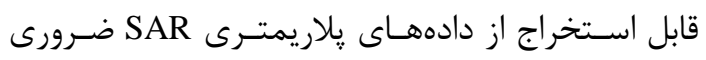

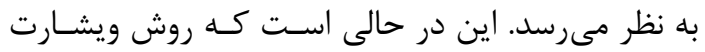

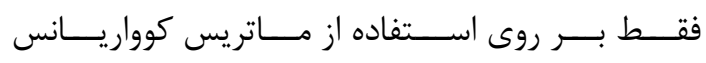

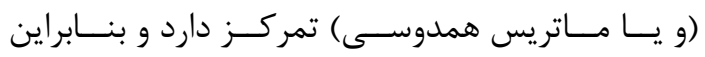

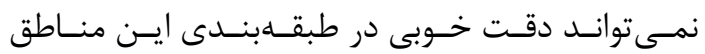

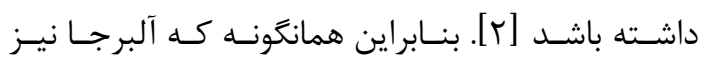

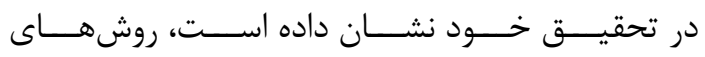

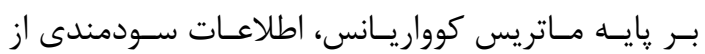




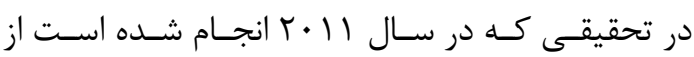

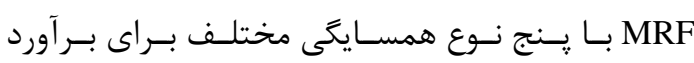

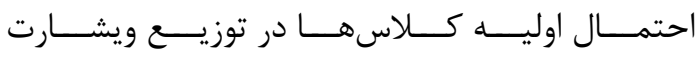

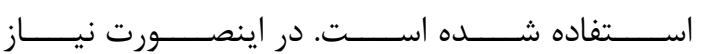

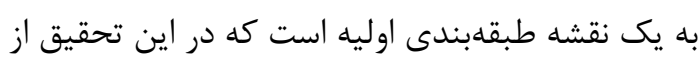

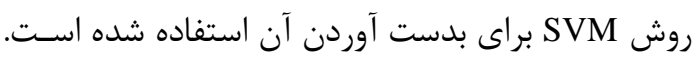

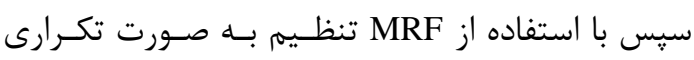

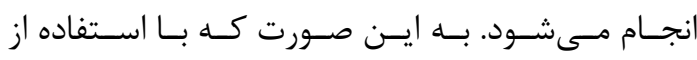

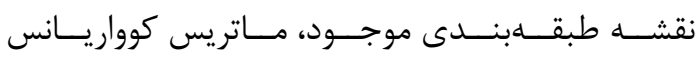
براى هر كلاس محاسبه مسىشـود و بـا اسـتفاده از آن،

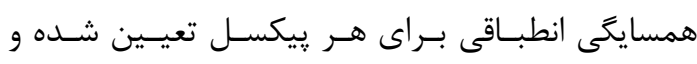

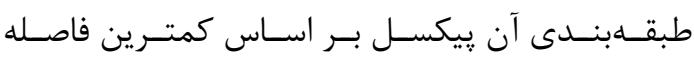

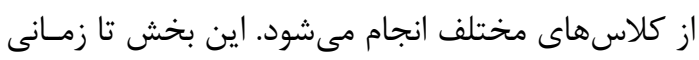

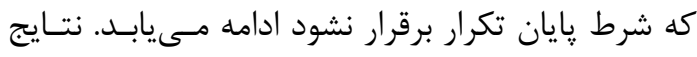

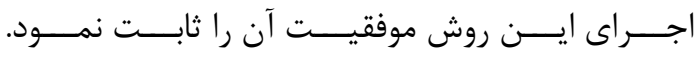

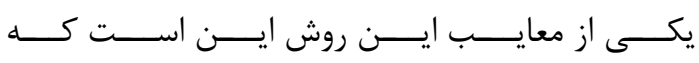

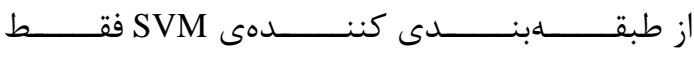

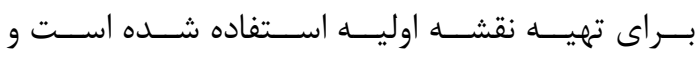

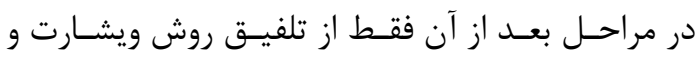

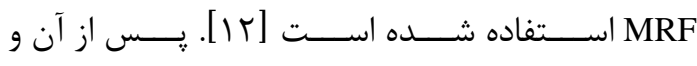

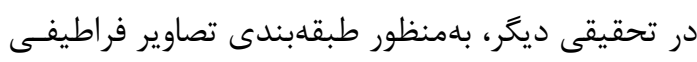

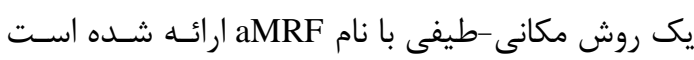

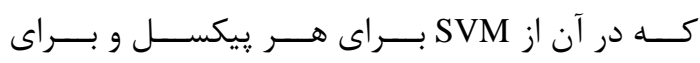

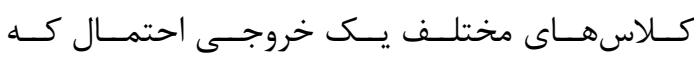

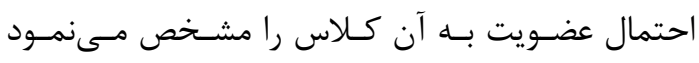

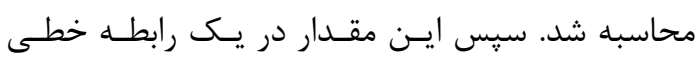

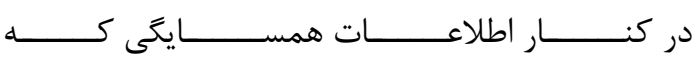

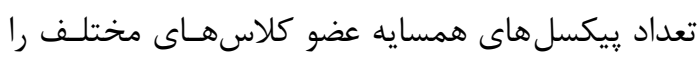

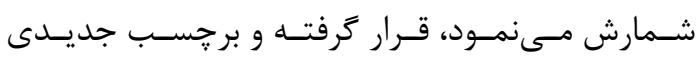

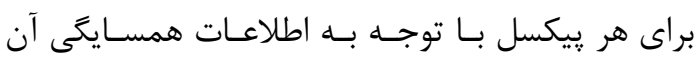

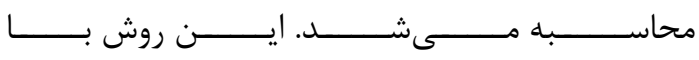

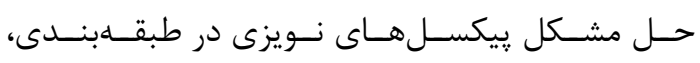

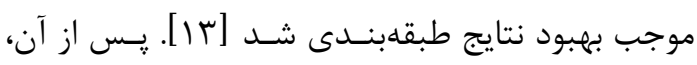

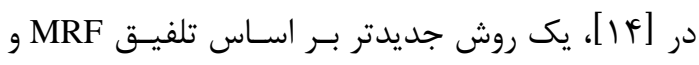

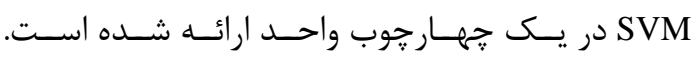

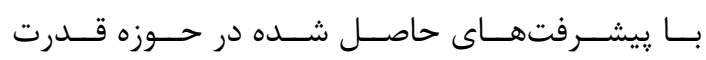

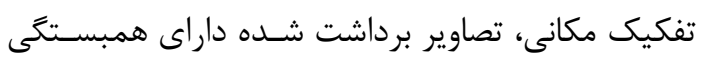

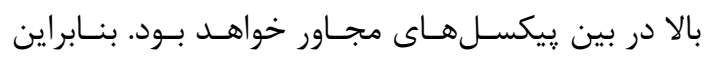

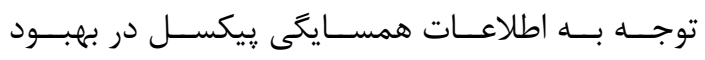

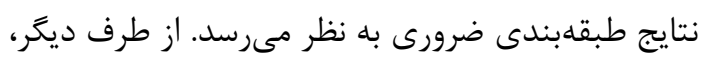

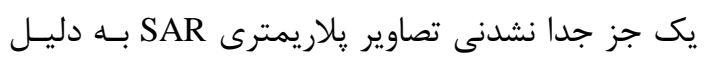

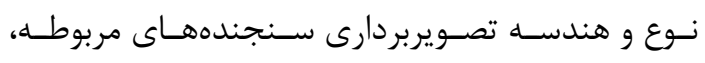

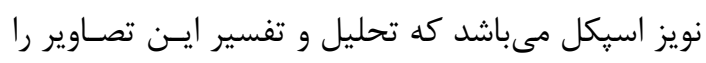

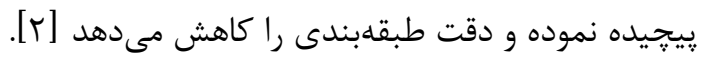

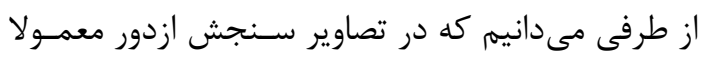

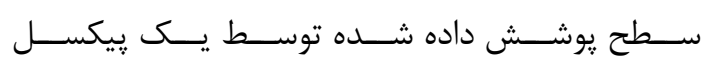

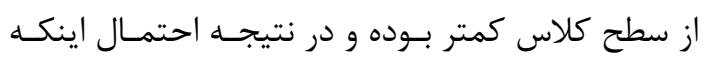

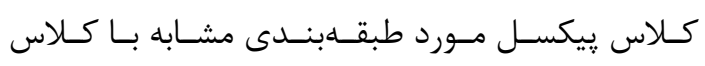

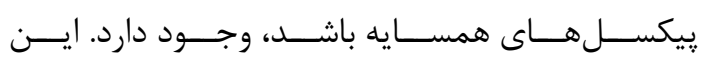

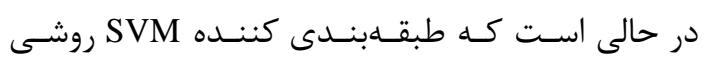

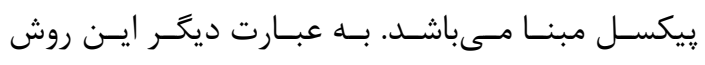

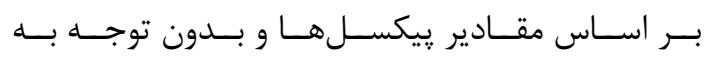

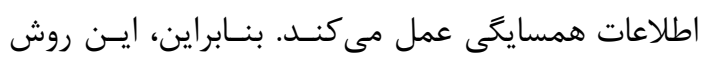

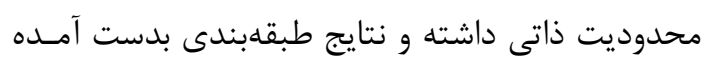

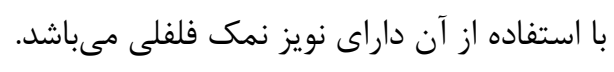

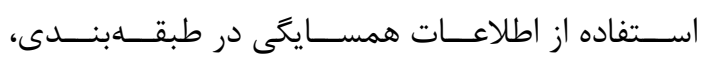
به عنوان يك منبـع اطلاعـاتى غنسى توصـيه مسى شـود.

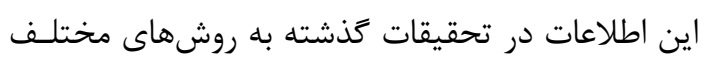

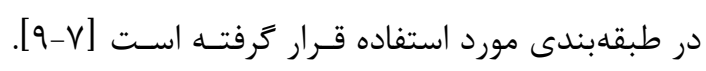

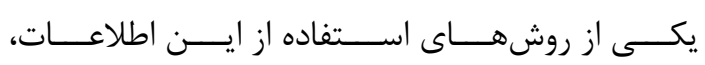

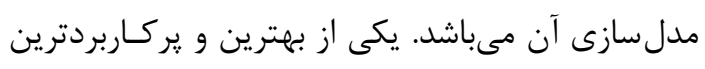

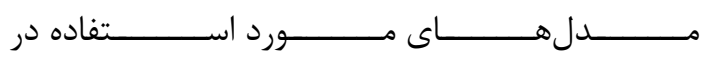
مدل سازى اطلاعات همسايكى، ميدان تصادفى مـاركوف

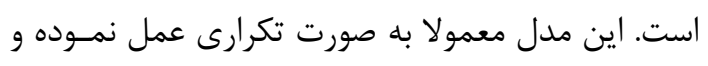

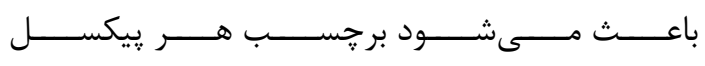

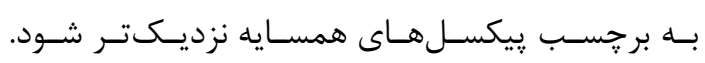
در تحقيقات انجام شده معمولا از مدل ماركوف در كنار

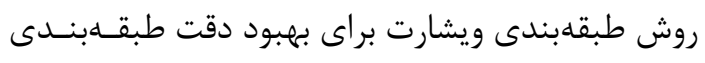
تصاوير يلاريمترى بوسيله مدل سـازى احتمـالات اوليسه

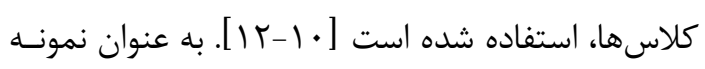


تعدادى از اين روشها داراى دقت كـافى نمسىباشــند و

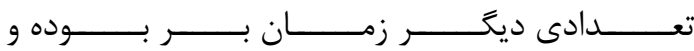

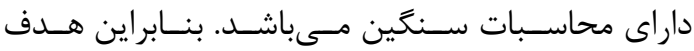

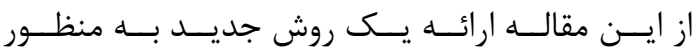
تلفيق SVM و مدل MRF است است است علاوه بر اينكه بتواند

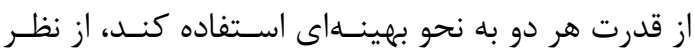
اجرا نيز زمانبر نباشد. در روش ارائه شده در اين مقاله،

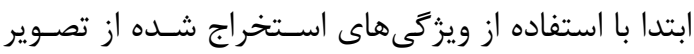

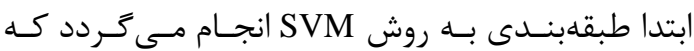

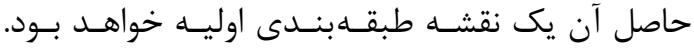

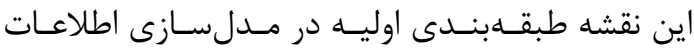

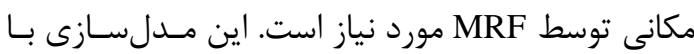

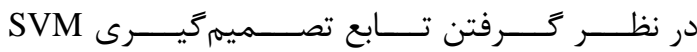

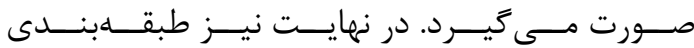
به صورت تكرارى انجام مى كيرد.

ايـن مقالـه از و بخـش تشـكيل شـده اسـت. بخـش ك شامل مبانى تئورى مـــتبط بـا ايسن تحقيـق مسىباشـد.

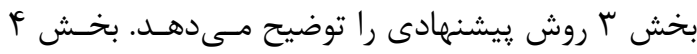

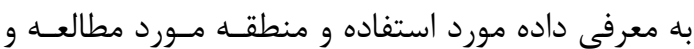

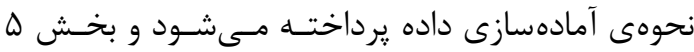

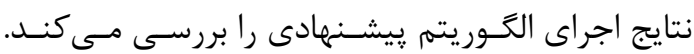
در نهايت نيز نتيجه گيرى و وِيشنهادات ارائه شده است.

\section{r- مبانى تئورى تحقيق}

\section{r-1 طبقهبندى به روش SVM}

روش SVM يك تابع خطى به نام f بين هـر دو كـلاس در يك فضاى تبديل يافته غير خطى محاسـبه نمـوده و از آن براى طبقهبنــى دو كـلاس اسـتفاده مسىنمايـد.

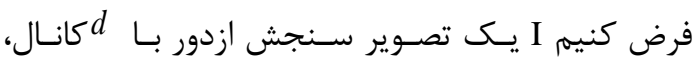

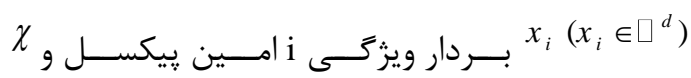

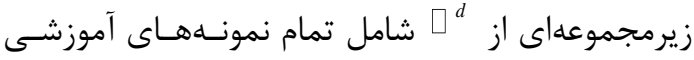

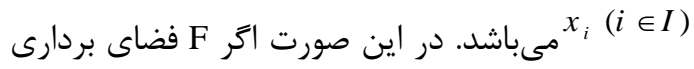

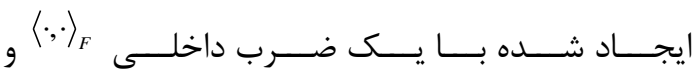
تبديل
اين روش بــين تـابع تصـميمكيـرى مـاركوين و كرنـلـ

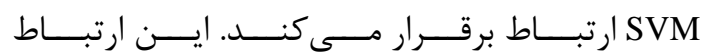

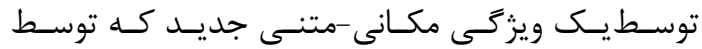
مدل سازى MRF به دست مى آيد و وارد كرنل مىشـود

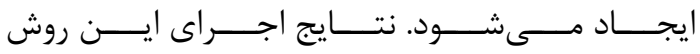

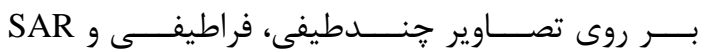

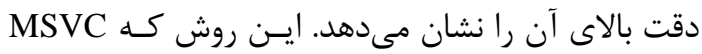

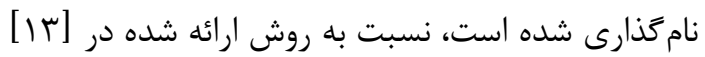

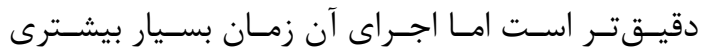

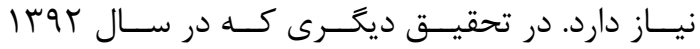

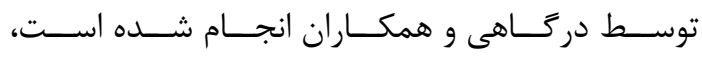

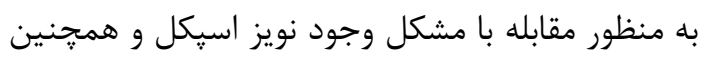

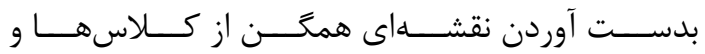

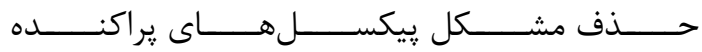

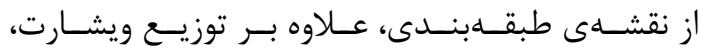

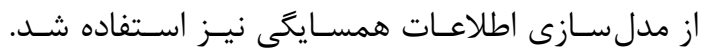

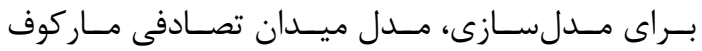

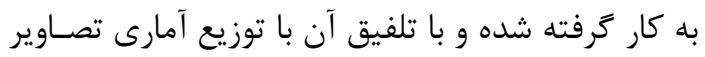

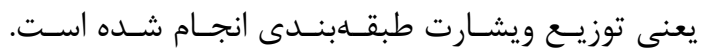

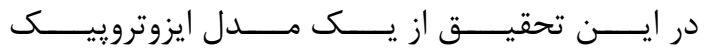

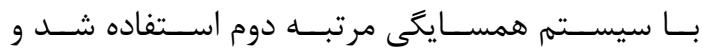

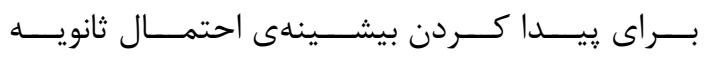

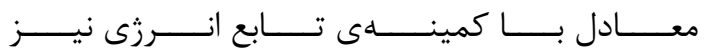

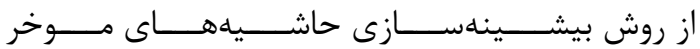

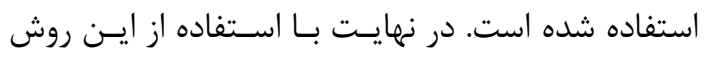

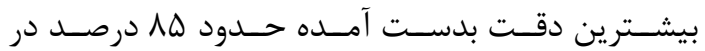

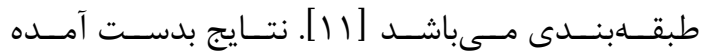

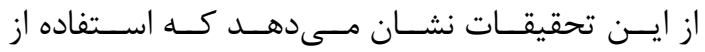

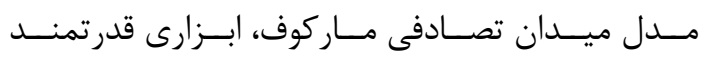
در مدلسـازى اطلاعـات همســايكى بـوده و تلفيـق آن آن

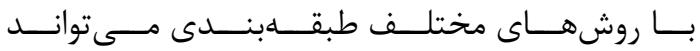

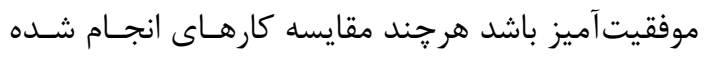
نشان از برترى طبقهبندى به روش SVM در مقايسه بـا استفاده از توزيع ويشـارت و قـانون بيـز دارد. متاسـفانه روشهاى ارائه شـده در اينجـا داراى دو مشـكل اسـت. 
$\mathrm{L} \propto$ ${ }_{\zeta} Q_{i j}=y_{i} y_{j} K\left(\mathrm{x}_{i}, \mathrm{x}_{j}\right),(\mathrm{i}, \mathrm{j} \in \mathrm{L})$

مجموعـهـ نمونـهـهـاى آموزشـى و C يـارامتر تعـديل در اين روش مىباشد.

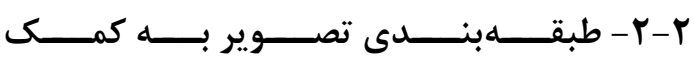
ميدان هاى تصادفى ماركوف

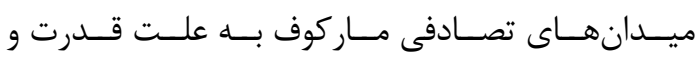

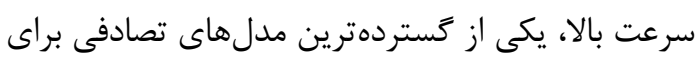

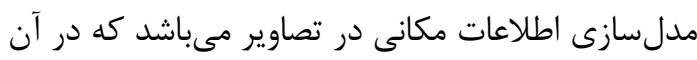

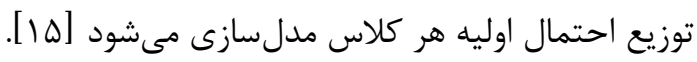
اخــر فــرض كنـيمم بر روى I باشد در اين صـورت

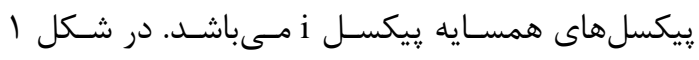

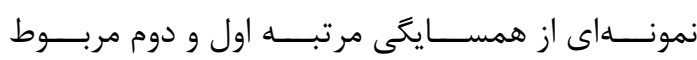

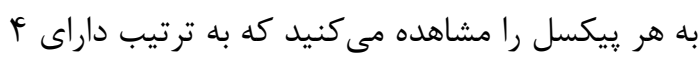
و ي بيكسل همسايه مىباشد.

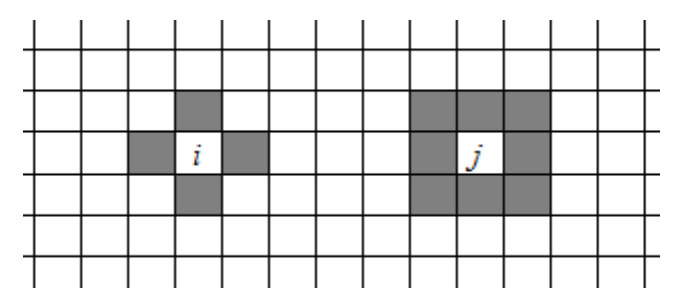
شكل ا: نمونههايى از سيستم همسايكى:

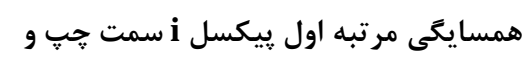
همسايكى مرتبه دوم ييكسل j در سمت راست نشان داده شده است.

ميدان برجسب

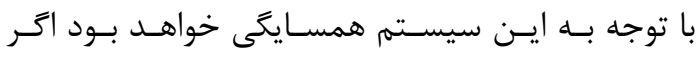

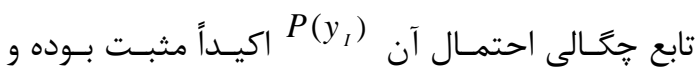
ويزگى ماركوينتى طبق رابطه ه برقرار باشد.

$$
P\left(\mathrm{y}_{i} \mid \mathrm{y}_{I-i i}\right)=P\left(\mathrm{y}_{i} \mid \mathrm{y}_{\partial_{i}}\right)
$$

(a) رابطه

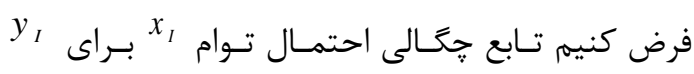

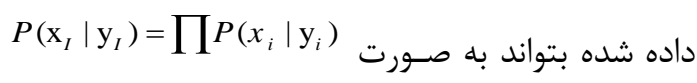

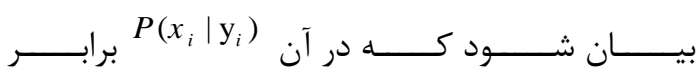

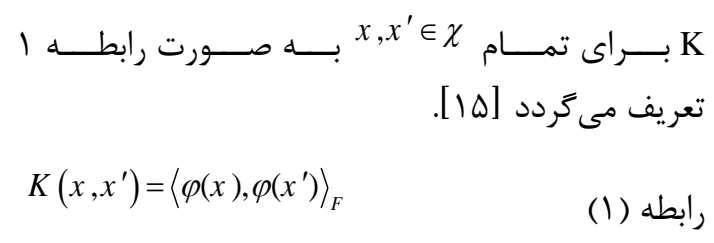

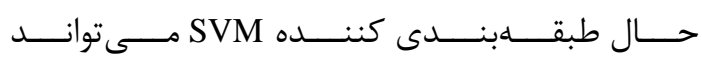
يك تابع جداكننده خطى به صورت رابطه ץ بيان شود. $f(x)=\langle w, \varphi(x)\rangle_{F}+b$

رابطه (r)

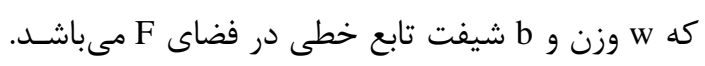

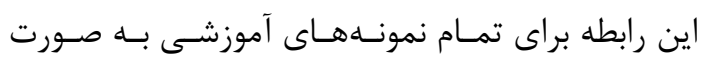

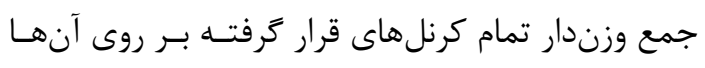

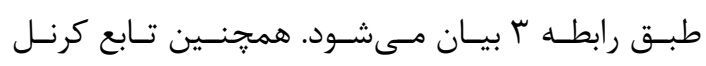

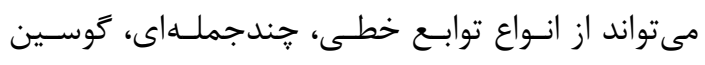

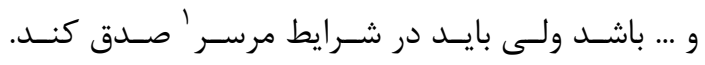

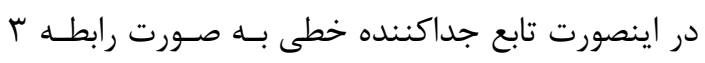

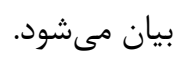
$f(x)=\sum_{j \in S} \alpha_{i} y_{j} K\left(x, x_{j}\right)+b$

رابطه (T)

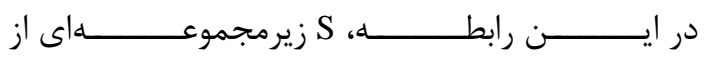

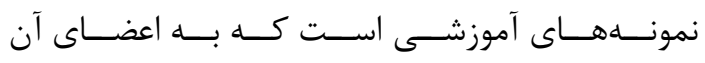

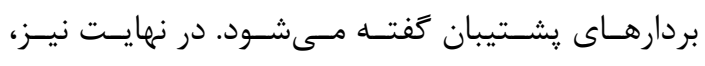

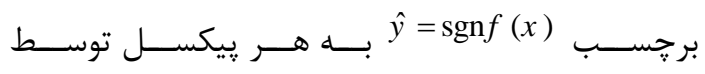

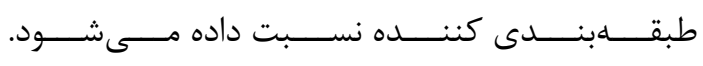
تعيين بردارهاى يشتيبان و محاسبه ضرايب

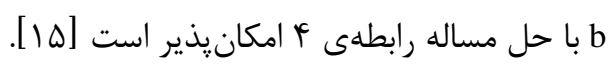

$$
\left\{\begin{array}{l}
\min _{\alpha \in \mathbb{\square}^{l}}\left(\frac{1}{2} \alpha^{T} Q \alpha-1^{T} \alpha\right) \\
\alpha \in[0, \mathrm{C}]^{l}, \quad y_{L}^{T} \alpha=0
\end{array}\right.
$$

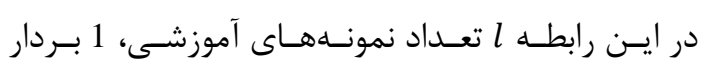

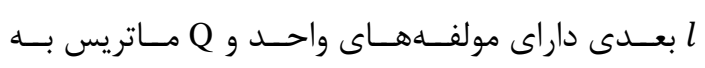

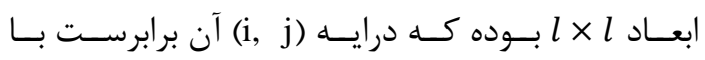

${ }^{1}$ Mercer 


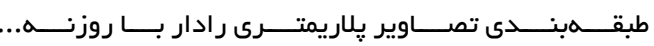

على مسجدى"، ياسر مقصودى ، محمدجواد ولدان زوج

اطلاعات مكانى است كه ايسن تلفيـق توسـط ٍـارامتر

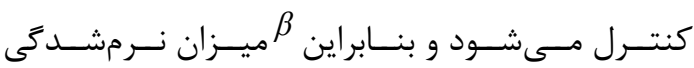

توسط MRF را مشخص مى كند [19]

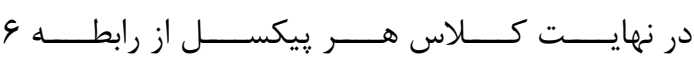
مشخص مى كَردد. به اين صورت كه مقدار انرزى ثانويسه

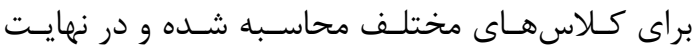

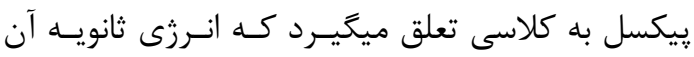
كمترين مقدار را داشته باشد.

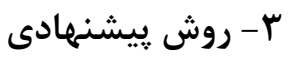

r-1- طبقدبندى تصوير به كمــ تلفيـق MRFو

Sوش SVM

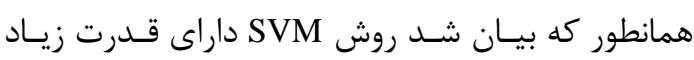

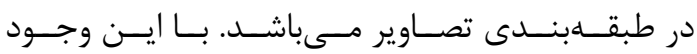

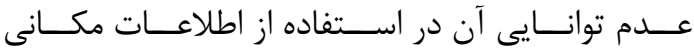
عيب اصلى اين روش مى باشد. بنابراين هدف ما در ايـن

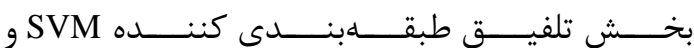
مدل ميدان تصادفى ماركوف به منظور اسـتفاده بهينـهـ

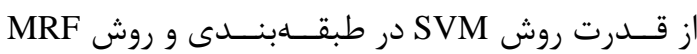

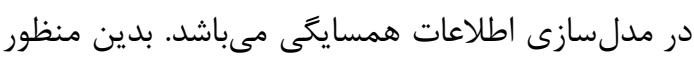
مىبايست بين روابط گ و و ارتباط منطقى برقرار كردد.

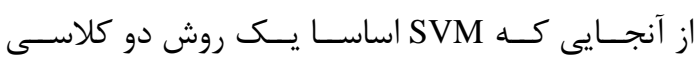

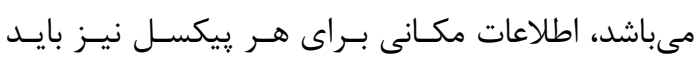

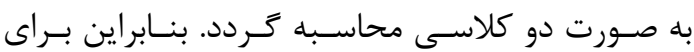

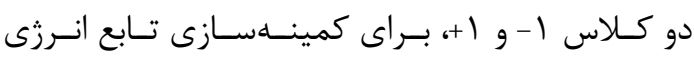

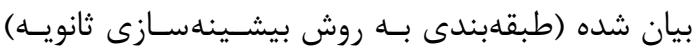

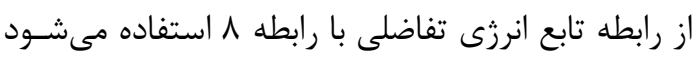

[lif]

رابطه (ᄉ)

$\Delta U_{i}\left(\mathrm{x}_{i}, \mathrm{y}_{\partial_{i}}\right)=U_{i}\left(-1 \mid \mathrm{x}_{i}, \mathrm{y}_{\partial_{i}}\right)-U_{i}\left(+1 \mid \mathrm{x}_{i}, \mathrm{y}_{\partial_{i}}\right)$

طبق رابطه 9 براى تابع انرزى تفاضلى مىتوان كفت:
با تابع קحكالى احتمال و و

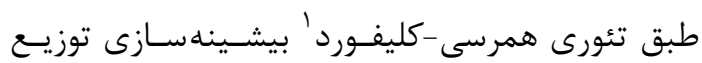

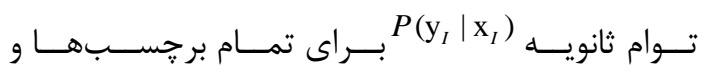

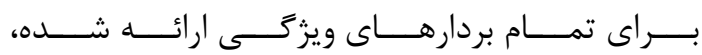

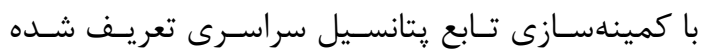

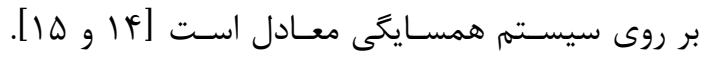

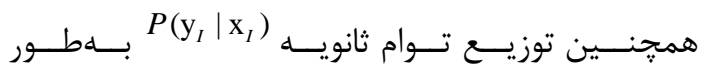

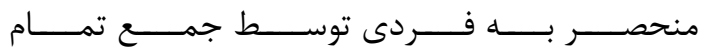
توزيــــــاى حاشـيهاى ثانويـهـ

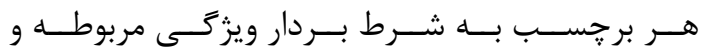

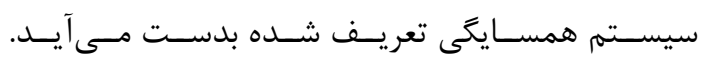

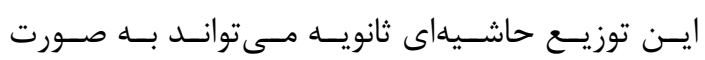

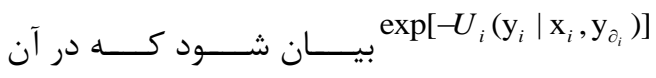

تابع انرزى ثانويه محلى بوده و از رابطـهـ $U_{i}\left(\mathrm{y}_{i} \mid \mathrm{x}_{i}, \mathrm{y}_{\partial_{i}}\right)$

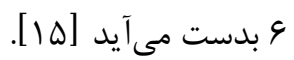
رابطه (9) $U_{i}\left(\mathrm{y}_{i} \mid \mathrm{x}_{i}, \mathrm{y}_{\partial_{i}}\right)=-\ln p\left(\mathrm{x}_{i} \mid \mathrm{y}_{i}\right)+\beta E_{i}\left(\mathrm{y}_{i} \mid \mathrm{y}_{\partial_{i}}\right)$

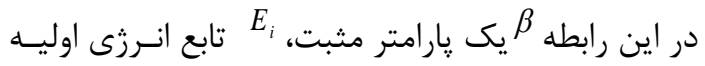
محلى مشخص كننده MRF انتخابى براى

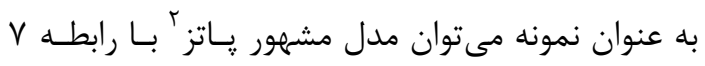
اشاره كرد [ع] [ب] $E_{i}\left(\mathrm{y}_{i} \mid \mathrm{y}_{\partial_{i}}\right)=-\sum_{j \in \delta_{i}} \delta\left(\mathrm{y}_{i}, \mathrm{y}_{j}\right)$ (V) رابطه كه در آن

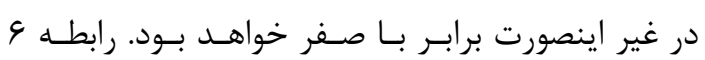

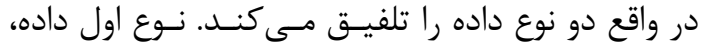

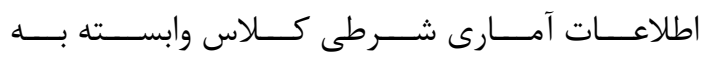

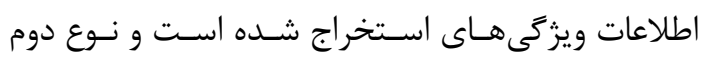

${ }^{1}$ Hammersley-Clifford

${ }^{2}$ Potts 
$\Delta U_{i}\left(\mathrm{x}_{i}, \mathrm{y}_{\partial_{i}}\right)=-\ln p\left(\mathrm{x}_{i} \mid \mathrm{y}_{-1}\right)+\ln p\left(\mathrm{x}_{i} \mid \mathrm{y}_{+1}\right)+\beta \varepsilon_{i}=\ln \frac{p\left(\mathrm{x}_{i} \mid \mathrm{y}_{+1}\right)}{p\left(\mathrm{x}_{i} \mid \mathrm{y}_{-1}\right)}+\beta \varepsilon_{i}$

(9) رابطه

نويز نمك-فلفلى در نتيجه طبقهبندى با استفاده از اين

$\varepsilon_{i}=E_{i}\left(-1 \mid \mathrm{y}_{\partial_{i}}\right)-E_{i}\left(+1 \mid \mathrm{y}_{\partial_{i}}\right), \quad \forall \mathrm{i} \in \mathrm{I}$

رابطه (·)

r-r- - مدل ميدان تصادفى ماركوف انطباقى مــل ميـدان تصـادفى مـاركوف مـورد اسـتفاده اغلـب

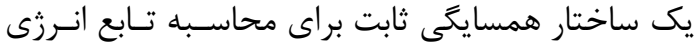

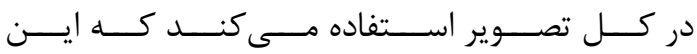

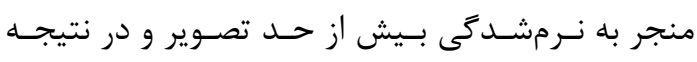

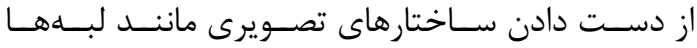

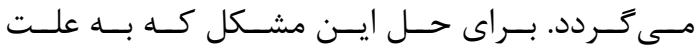

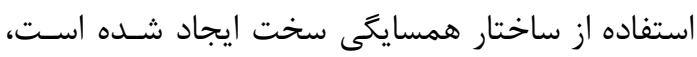
تعدادى مدل تصادفى ماركوف انطباقى ارائه شده اسـت

. [tr-t.]

در بعضى از اين مدلهاى ارائه شده، ميزان همگن بودن

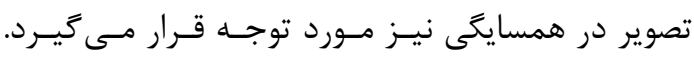

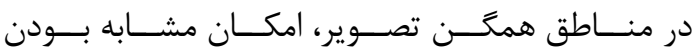

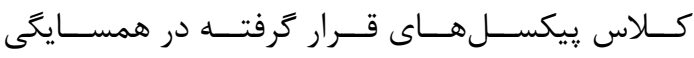
ييكسل مورد مطالعه بيشتر خواهــد بـود در حــالى كـهـ

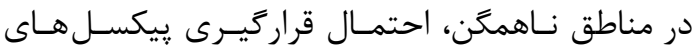
بـا كـلاسهـاى متفــاوت در همســايكى بيشـتر اسـت.

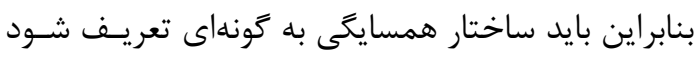

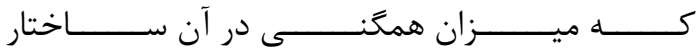

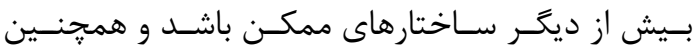

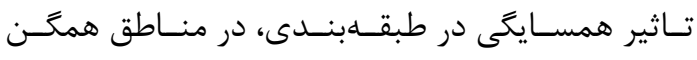

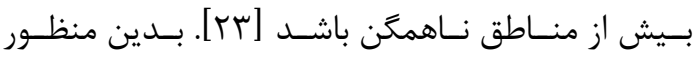
در اين مقاله از ساختار همسايكى انطبـاقى و همجنــين

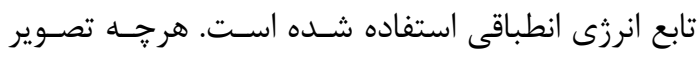

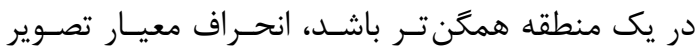

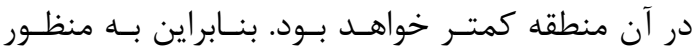

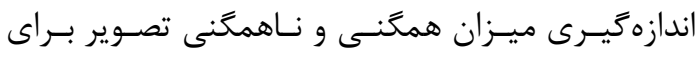
ييكسل هاى مختلف تصوير، از اندازهخيرى انحراف معيار در همسايگى هر ييكسل استفاده مىشود.
رابطــه 9 از دو عبــارت جداكانــه تشـكيل شـده اسـت.

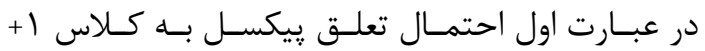

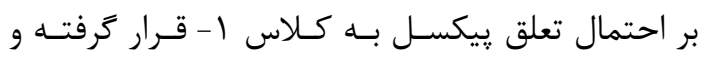

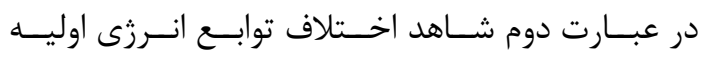
مربوط به دو كلاس هستيم. عبـارت دوم بـا اسـتفاده از

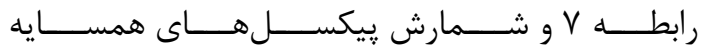

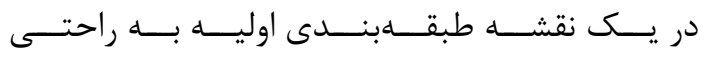
قابل محاسبه است. براى محاسبه عبارت اول توجه شود

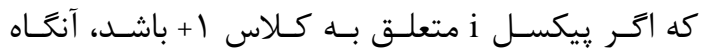
و در اينصــ $p\left(\mathrm{x}_{i} \mid \mathrm{y}_{+1}\right)>p\left(\mathrm{x}_{i} \mid \mathrm{y}_{-1}\right)$

i خواهـد بـود. متقــابلا اخـر ريكسـل $\ln \frac{p\left(\mathrm{x}_{i} \mid \mathrm{y}_{+1}\right)}{p\left(\mathrm{x}_{i} \mid \mathrm{y}_{-1}\right)}<0$

متعلـق بــه كـلاس 1- باشـد، آنغــاه خواهد بود. اين مساله دقيقا مشابه روش محاسبه كلاس هر ريكسل توسط تابع تصـميم گيسرى SVM مـىباشـد. در مساله SVM در رابطه ب نيز هر كاه ييكسل به كلاس 1+، و هر Fاه 0 > (x) به كلاس 1 - تعلق دارد. بنابراين با توجه به شباهت تابع تصميمزيرى SVM و عبارت اول رابطه 9 داريه:

) رابطه (1) $\Delta U_{i}\left(\mathrm{x}_{i}, \mathrm{y}_{\partial_{i}}\right)=f(x)+\beta \varepsilon_{i}=\sum_{j \in S} \alpha_{i} y_{j} K\left(x, x_{j}\right)+b+\beta \varepsilon_{i}$

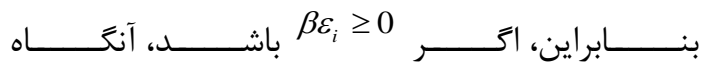
و اگر $\Delta \varepsilon_{i}\left(\mathrm{x}_{i}, \mathrm{y}_{\partial_{i}}\right) \geq f_{S V M}(x)$ خواهـ $\Delta U_{i}\left(\mathrm{x}_{i}, \mathrm{y}_{\partial_{i}}\right)<f_{S V M}(x)$ اين بدان معنى است كه ابر صـفحه بــراى هـر ريكسـل

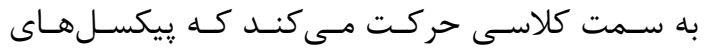

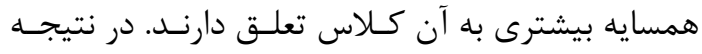




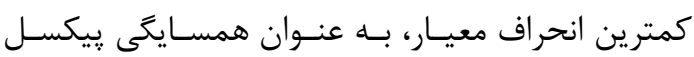

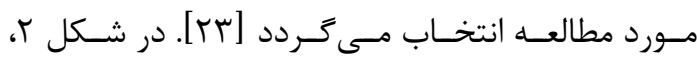
ساختارهاى همسايكى مختلف نشان داده شده است كه

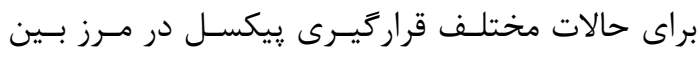

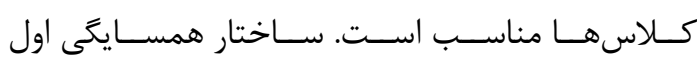

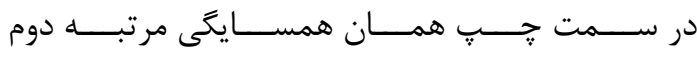

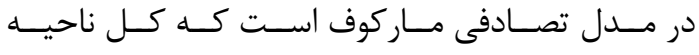

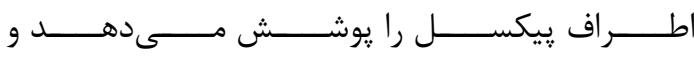
در مناطق بسيار همعَن انتخاب مى رَّرد. r-r-1- - ساختار همسايخى انطباقى

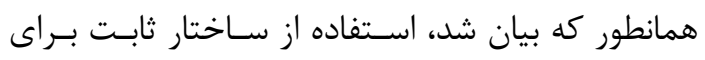

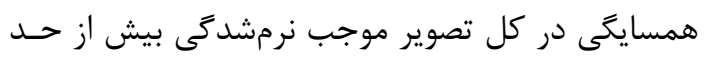

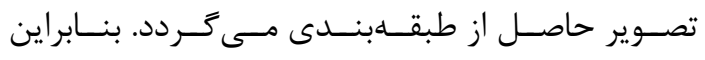

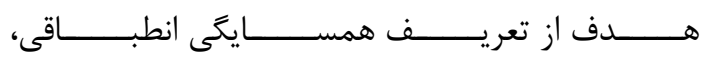

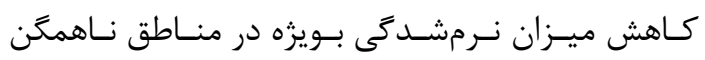

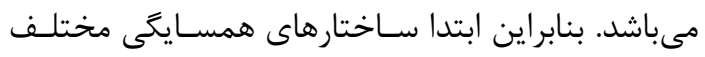

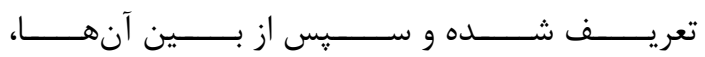

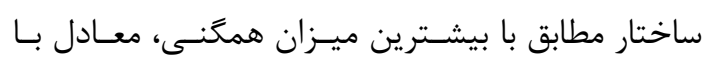

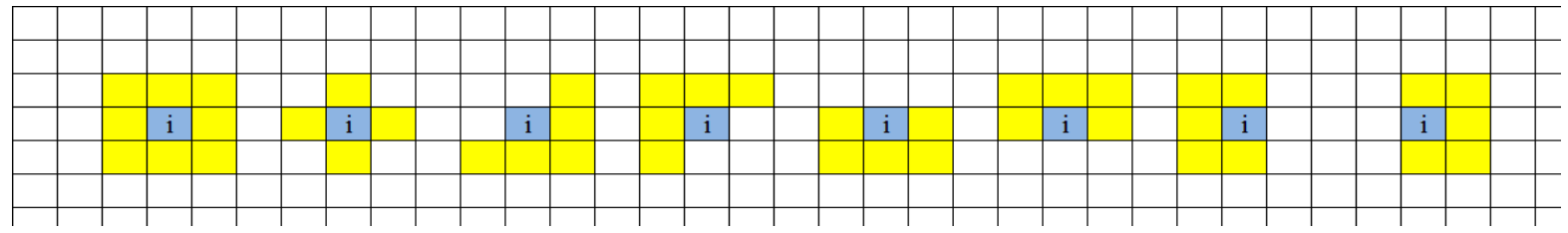
شكل r: انواع سيستمهاى همسايكى براى يِيكسل i مورد استفاده در اين مقاله.

اين ضريب براى هر ييكسل با قرارگيرى يك بنجـــهـــا

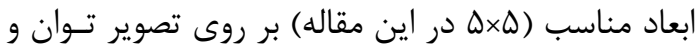

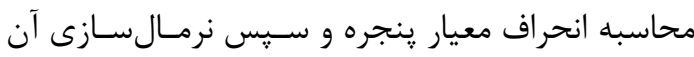

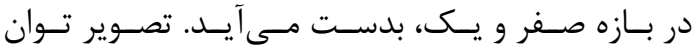
در دادههاى يلاريمترى از جمع مقادير ماتريس يراكنش

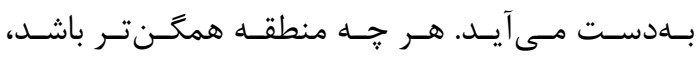

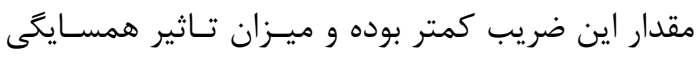
در تابع انرزى بيشتر خواهد بود. از طرفى در مناطق مرز

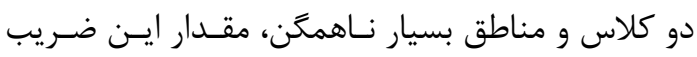

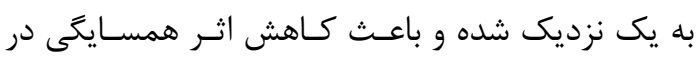
طبقهبندى مى گردد.

\section{r-r- الكوريتهم روش پييشنهادى}

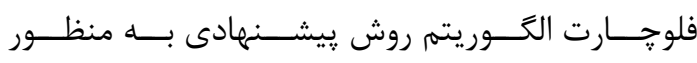

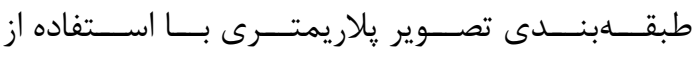

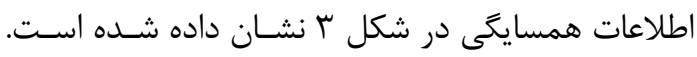

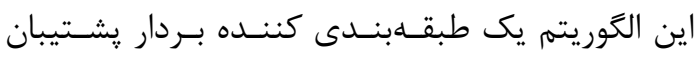

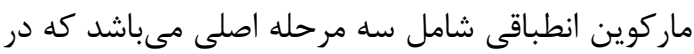
اين بخش شرح داده مىشود.

\section{r-Y-r-r-r ساختار همسايگى انطباقى}

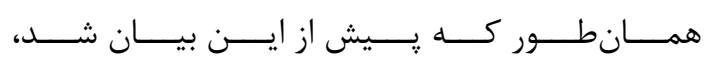

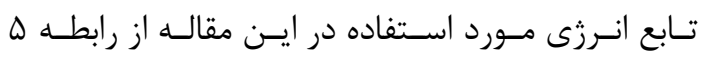

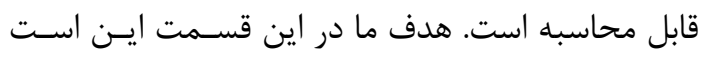

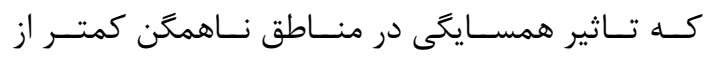

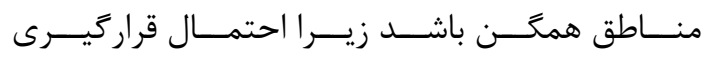

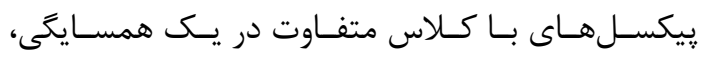

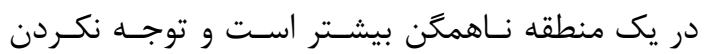

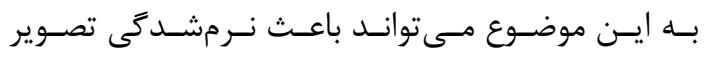

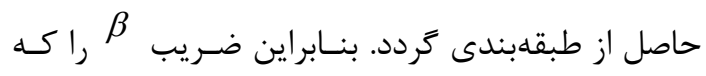

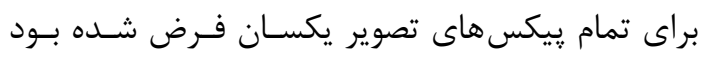
را به صورت زير تغيير مى دهيهم.

$\beta_{i}=\beta\left(1-s t d_{i}\right)$

رابطه (IT)

در اينصورت براى هر پِيكسل تاثير اطلاعات همسـايكى

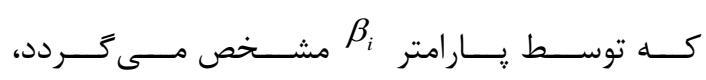

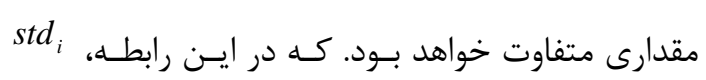

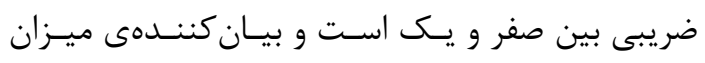
ناهمكنى در همسايكى بيكسل مورد مطالعه مس بـاشـد. 


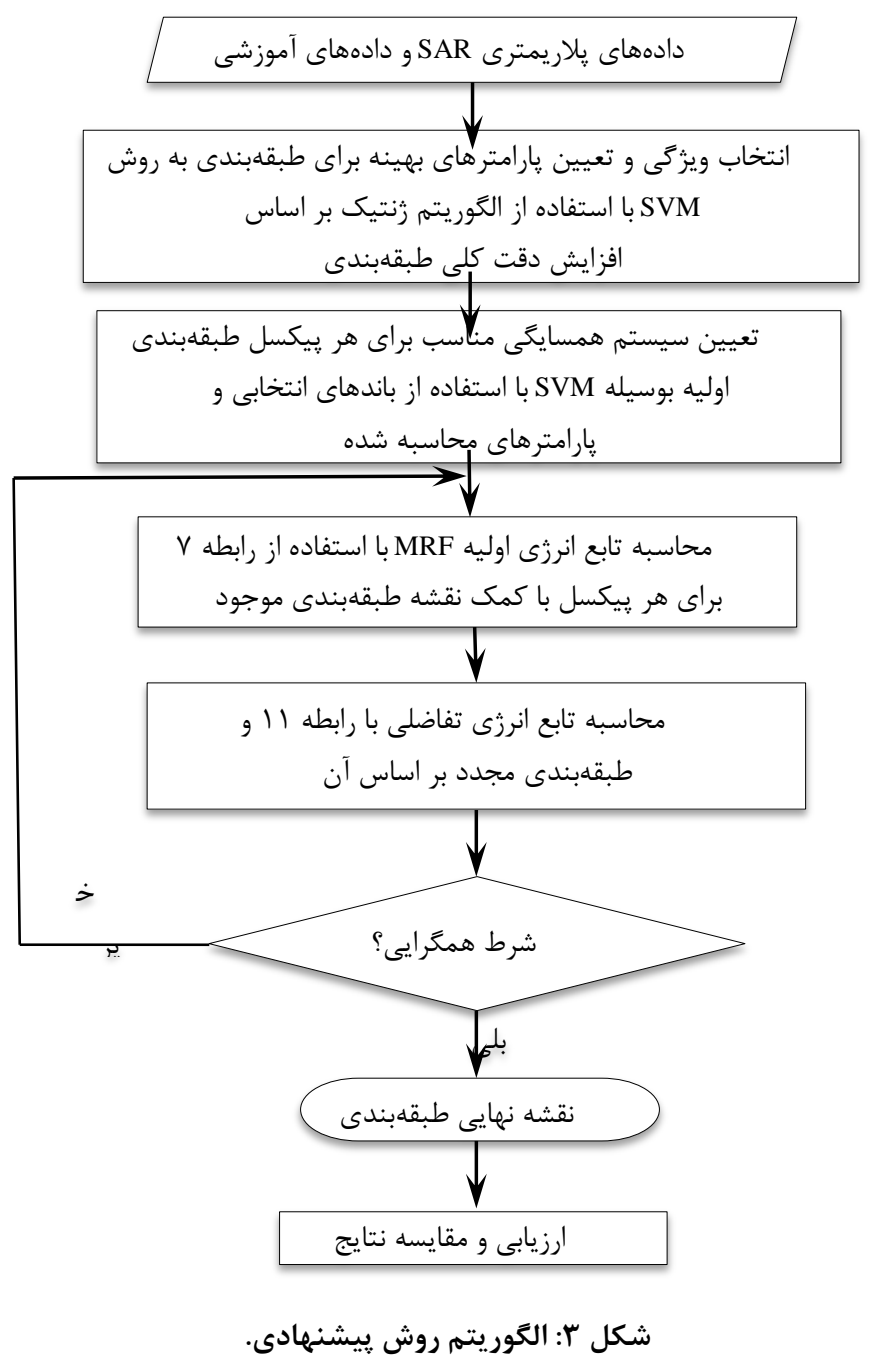

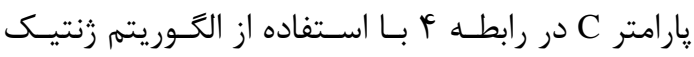
تعيين مى كردد.

$$
K\left(x, x^{\prime}\right)=\exp \left(-\frac{\left\|x-x^{\prime}\right\|^{2}}{2 \sigma^{2}}\right)
$$

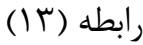

طبقهبنـدى SVM بـهـ روش يــ در برابـر يـــ انجـام

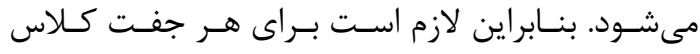

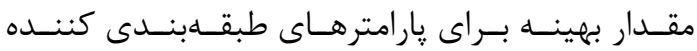

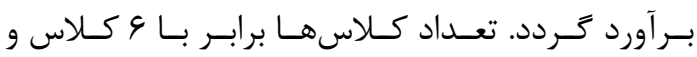

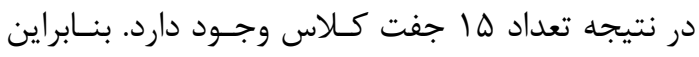
نحوه كد نمودن مساله به صورت زير مىباشد.

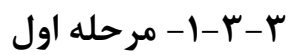
در اين مرحله انتخاب ويزگگ و تعيين يارامترهاى بهينه

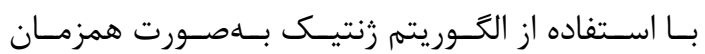

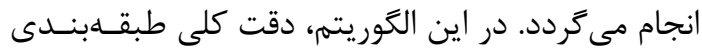
بهعنوان معيار ارزيابى استفاده شده است. در اين مقالـه دئه

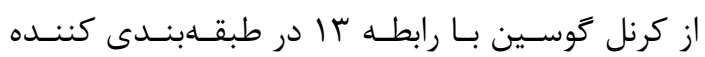
استفاده مى گردد. از تصـوير يلاريمتـرى موجـود،

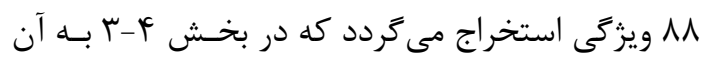

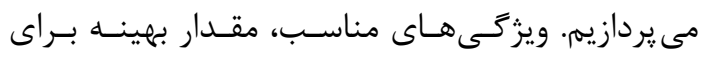

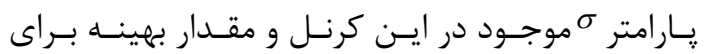




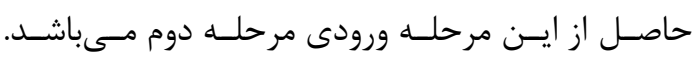

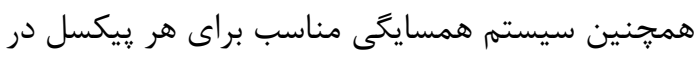
اين مرحله تعيين مىشود.

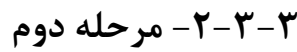

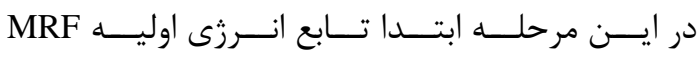

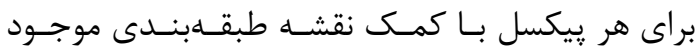

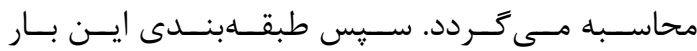

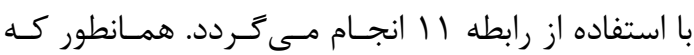

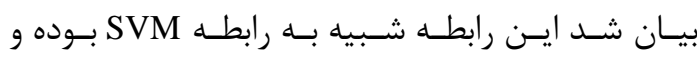

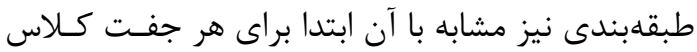

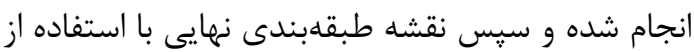

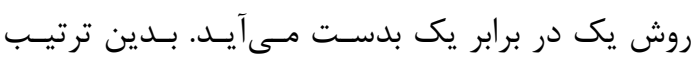

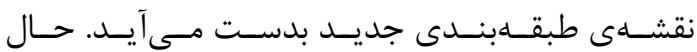
شرط همكر ايى بررسى مىشود بـدين صـورت كـهـ اخـر

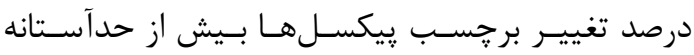

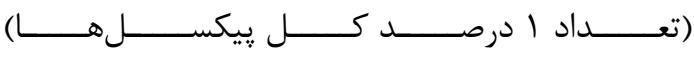
در نظر گرفته شده باشد، اين مرحلـه تكـرار مسى دـردد.

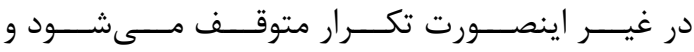

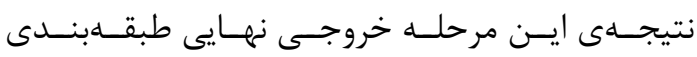
خواهد بود. در نهايت نيز ارزيابى روش مـورد اسـتفاده و

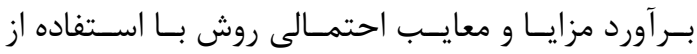

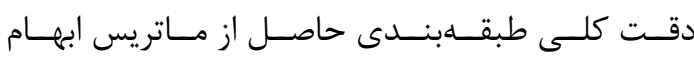

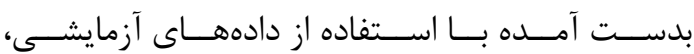

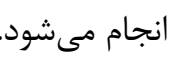

ץ- منطقه مطالعاتى و آمادهسازى داده F - - - منطقه مطالعاتى و داده اوليه

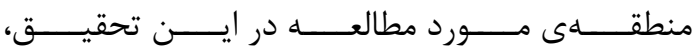

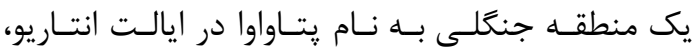

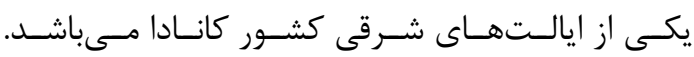

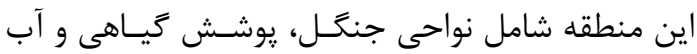

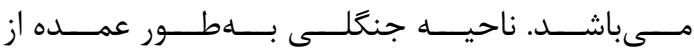
درختان نرم קوب و سخت هوب تشكيل شده است كه

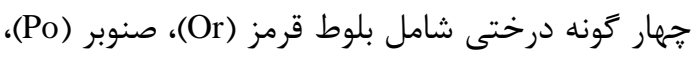

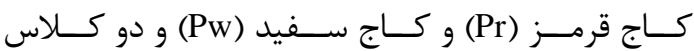

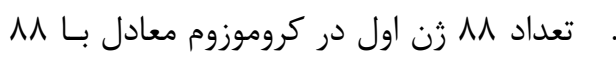

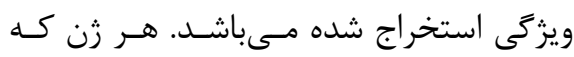

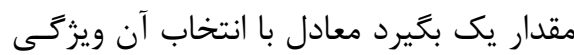

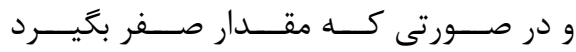
به معناى نامناسب بودن آن ويزگگى مى صباشد.

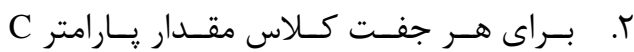
مىتواند بين صفر تا . .ا تغيير كند. بنابراين

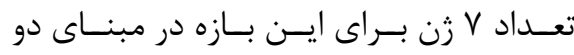

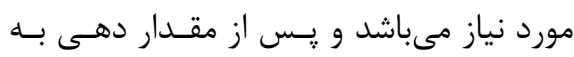

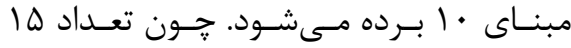

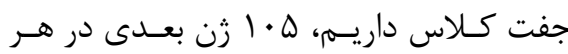
كروموزوم به اين پارامتر اختصاص مىيابد.

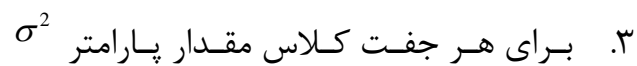

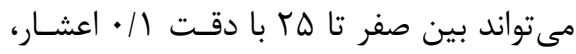
تغيير كند. بنابراين تعداد ^ زن براى اين بازه

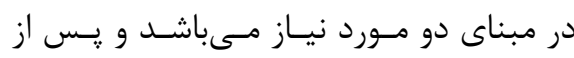

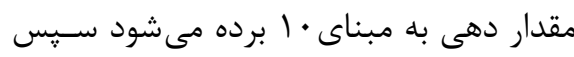

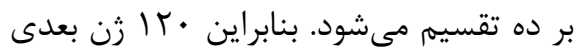

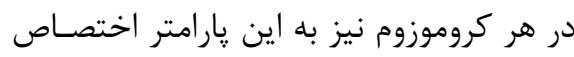

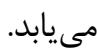
در مجموع هر كروموزوم بـه تعـداد ساب زن نيـاز دارد.

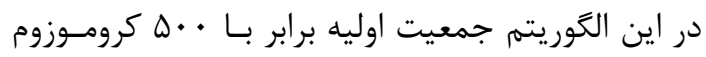

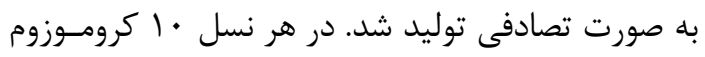

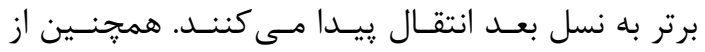

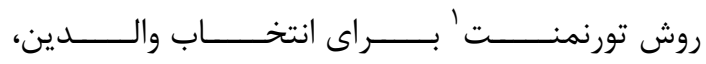

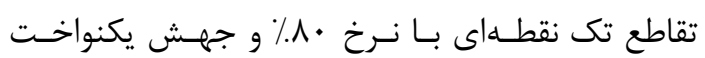

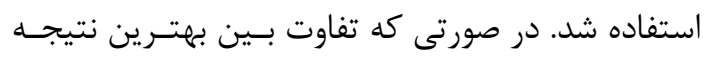

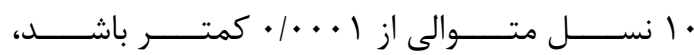
الكوريتهم متوقف خواهد شد.

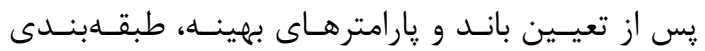

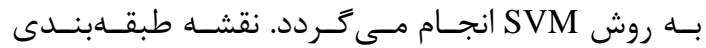

${ }^{1}$ Tournament 
براى استخراج يارامترهاى تجزيه و طبقهبندى مورد نياز

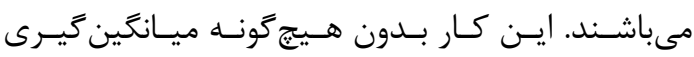

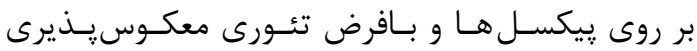
تارحت

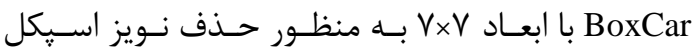

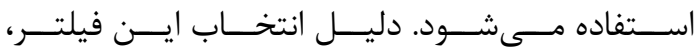

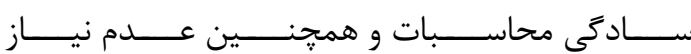

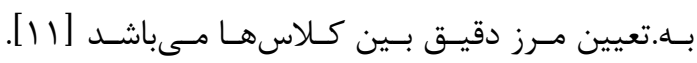

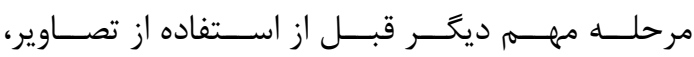

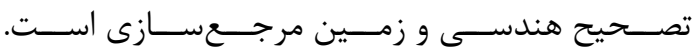

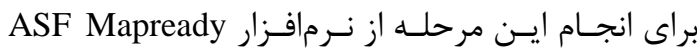

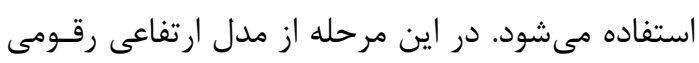

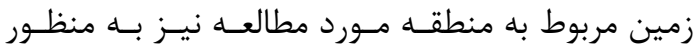

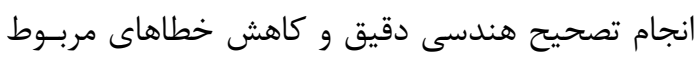

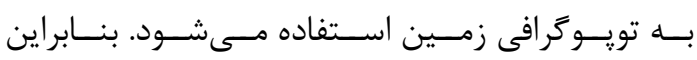

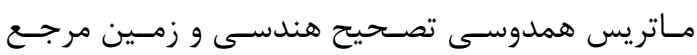

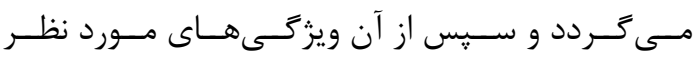

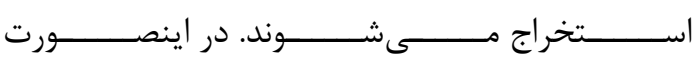

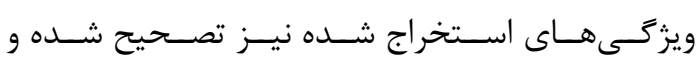

$$
\text { زمين مرجع مىباشند. }
$$

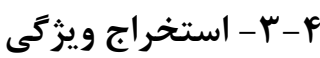

در اين مقاله از ويزگكىهـاى مختلـف قابـل اسـتخراج از

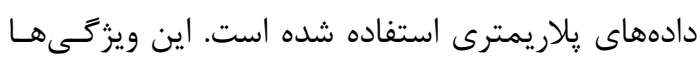

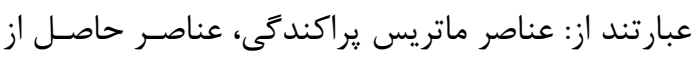

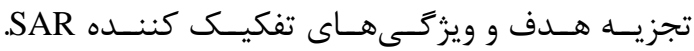

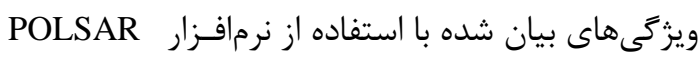

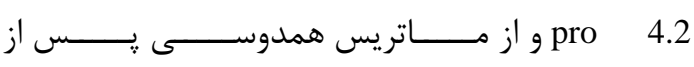

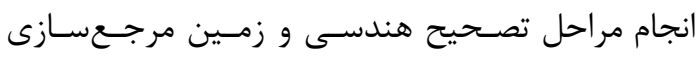

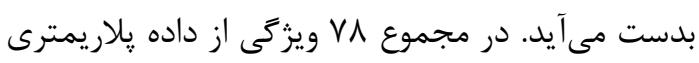

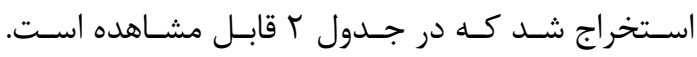

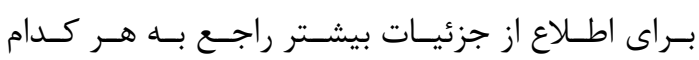
از اين ويزگى ها به مرجع [ب] مراجعه شود.

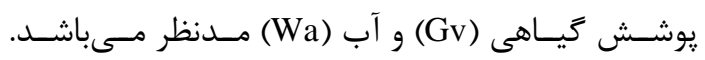

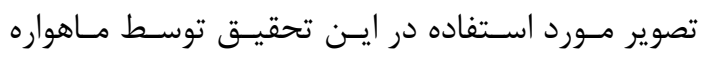

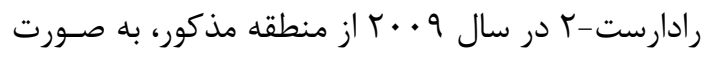

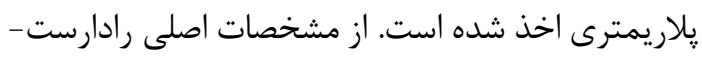

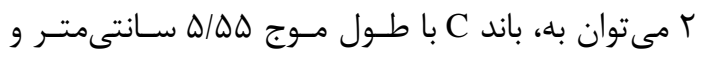

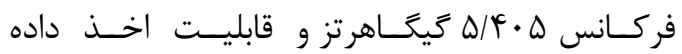

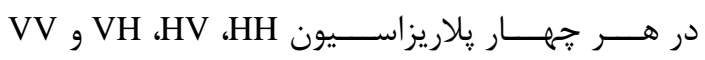
اشاره كرد. تصاوير در حالت 'SLC بوده و قدرت تفكيك

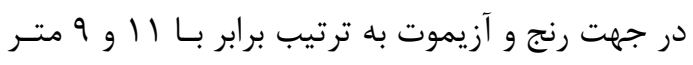

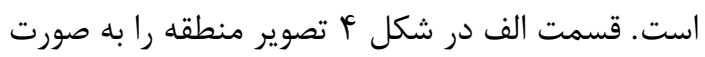

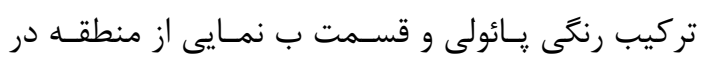

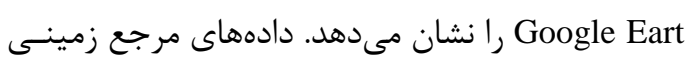

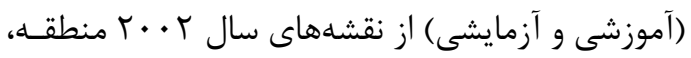

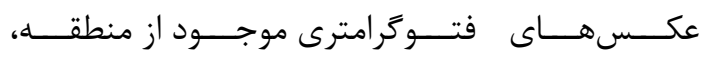

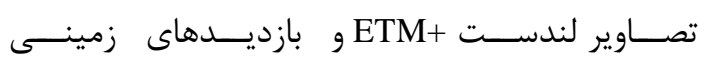

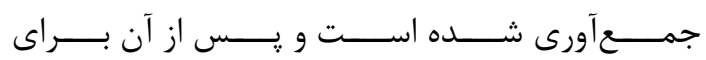

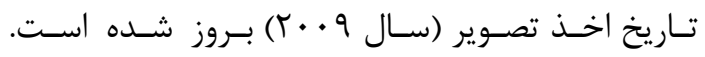

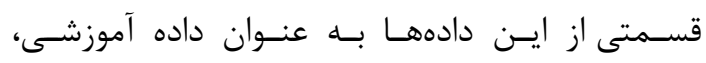

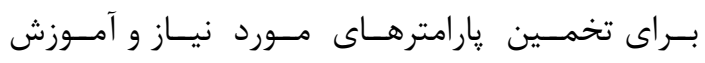

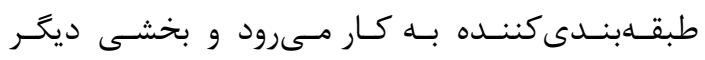

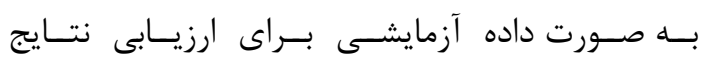

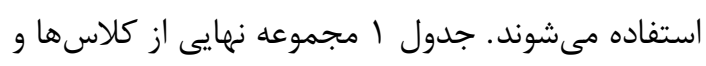

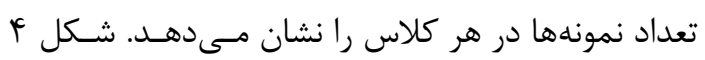

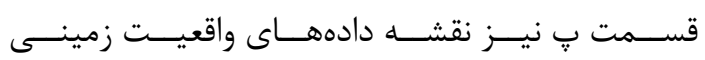

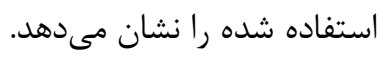

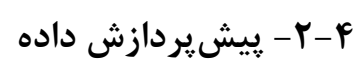

جهت آمادهسازى و آناليزهاى اوليه تصـاوير از نـرمافـزار

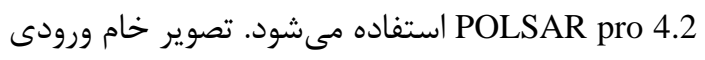

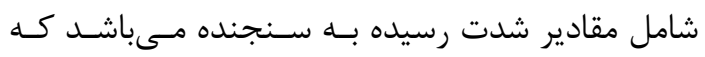

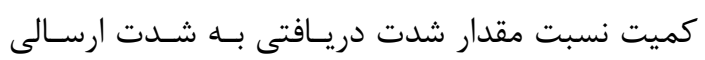

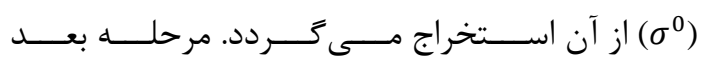

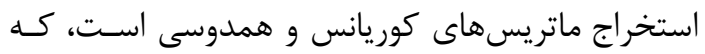

${ }^{1}$ Singe Look Complex 


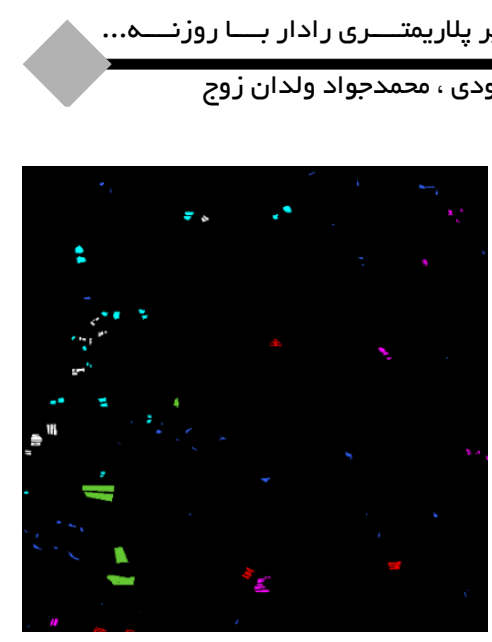

(ֶ)

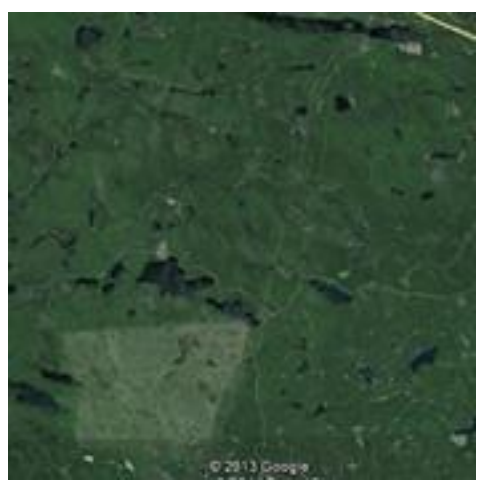

(ب)

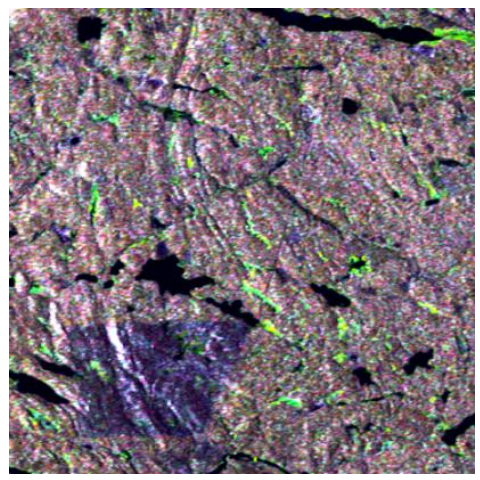

(الف)

شكل f: نمايى از منطقه: (الف) زير تصوير مورد استفاده به صورت تركيب رنكى پائولى، (ب) منطقه مورد مطالعه در Google Earth و (ب) (ب) نقشه واقيت زمينى.

\begin{tabular}{|c|c|c|c|}
\hline تعداد نمونه آزماسيشى & تعداد نمونه آموزشى و آمهاى & توضيح & كلاس \\
\hline AAT & VVE & بلوط قرمز & $\begin{array}{l}\mathbf{O} \\
\mathbf{r}\end{array}$ \\
\hline VIF & AFD & صنوبر & Po \\
\hline १^९ & SFD & كاج قرمز & Pr \\
\hline$\Delta T$. & FTD & كاج سفيد & $\begin{array}{l}\mathbf{P} \\
\mathbf{w}\end{array}$ \\
\hline IVVE & $1 \Delta \& V$ & يوشش تياهى & $\begin{array}{l}\mathbf{G} \\
\mathbf{v}\end{array}$ \\
\hline GTr & GAT & آب & $\begin{array}{l}\mathbf{W} \\
\mathbf{a}\end{array}$ \\
\hline$\Delta F \|$ & faYA & مجموع & \\
\hline
\end{tabular}

جدول r: ويزَىىهاى يلاريمترى مورد استفاده در اين تحقيق

\begin{tabular}{|c|c|c|}
\hline ت تعداد ويزگى & ت توصيف & ويز"ى \\
\hline 11 & Scattering, Covariance, and Coherency matrix elements & ويزگى هاى اصلى \\
\hline$\Delta 9$ & Huynen, H / A / $\alpha$, Yamaguchi, Touzi, Barens, Freeman, Holm & ويزگى هاى حاصل از تجزيه \\
\hline 11 & $\begin{array}{l}\text { SPAN, Pedestal height, Degree and completely polarization extrema, } \\
\text { Received power extrema, Correlation coefficients, Depolarization ratio, } \\
\text { Fractional polarization }\end{array}$ & توصيف كنندههاى SAR \\
\hline
\end{tabular}

بلهدست آمده از ماتريس ابهام، آنها را مقايسه مى كنيم.

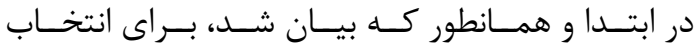

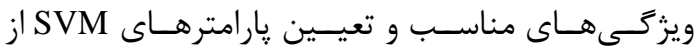

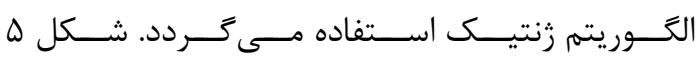

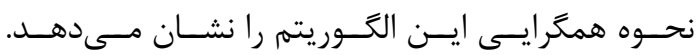

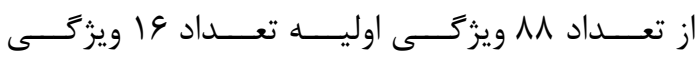

$$
\text { ه- ن- ايج تجربى }
$$

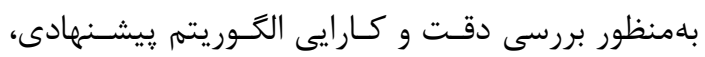

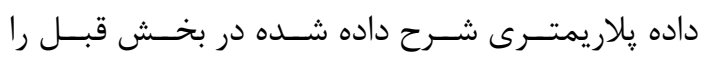

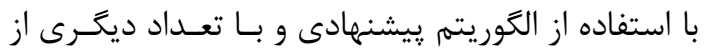

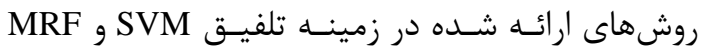

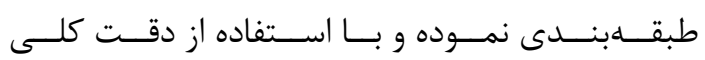


كه براى مقايسه بكار كرفته شده اند روشهاى ويشارت

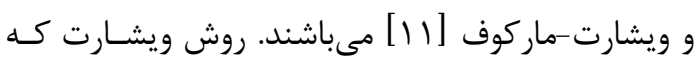

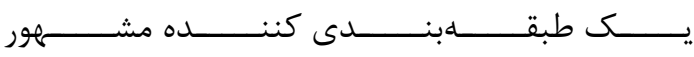
در زمينه طبقهبندى دادهاى يلاريمترى بوده و معمولا براى مقايسه به عنوان يك روش يايه استفاده مى گتردد.

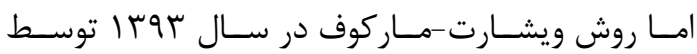

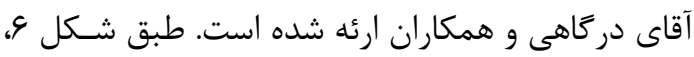

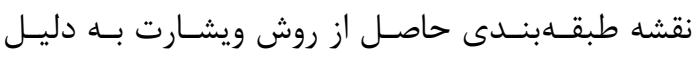

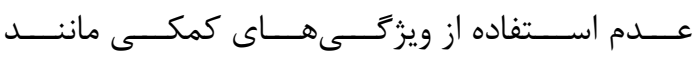

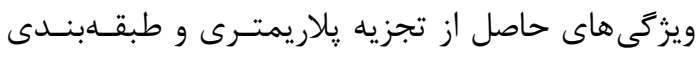

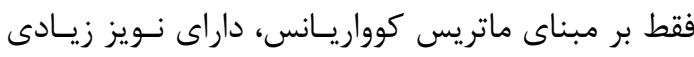

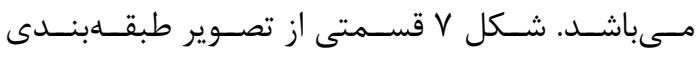

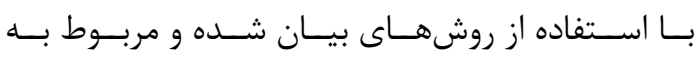
كلاس يوشش گياهى نشان داده شده است.

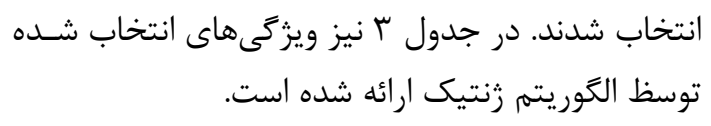

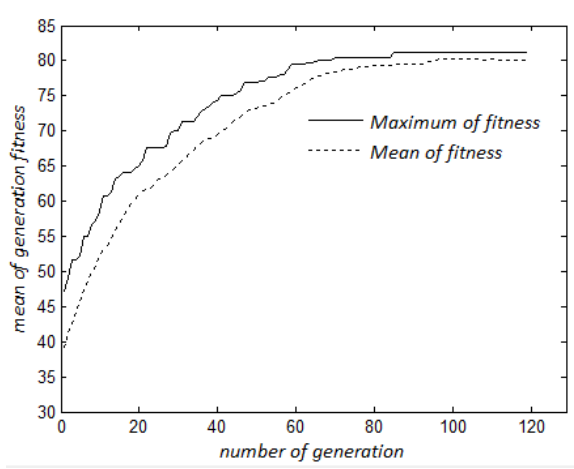

شكل ه: نحوه همكَرايى الكَوريتم زنتيك.

شكل و تصـاوير حاصـل از طبقـهـبنـدى بــا اسـتفاده از روش هاى مختلف و الكوريتم بِيشنهادى (SVM-MRF)

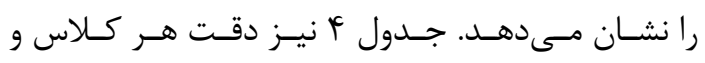

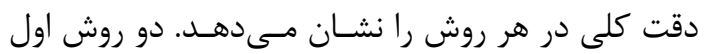

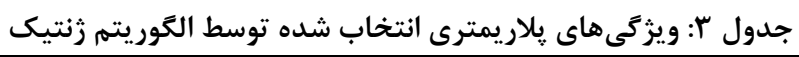

\begin{tabular}{|c|c|c|}
\hline تعداد ويزگى & توصيف & 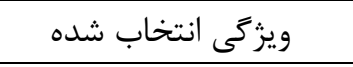 \\
\hline r & Coherency matrix $\left[\mathrm{T}_{12}, \mathrm{~T}_{22}, \mathrm{~T}_{23}\right]$ & ويزگى هاى اصلى \\
\hline $1 \cdot$ & $\begin{array}{r}\text { Huynen }\left[\mathrm{T}_{33}\right], \text { Barens }\left[\mathrm{T}_{22}\right], \text { Holm }\left[\mathrm{T}_{11}\right], \mathrm{H} / \mathrm{A} / \alpha[\mathrm{H}, \text { Eigenvalue }(1)], \\
\text { Freeman[Odd, Dbl], Yamaguchi[Odd, Helix], Touzi }[\psi]\end{array}$ & 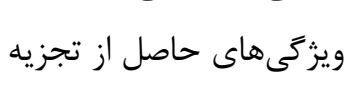 \\
\hline r & Pedestal height, Correlation coefficients $\left[\mathrm{Ro}_{12}\right]$, Degree of polarization & توصيف كنندههاى SAR \\
\hline
\end{tabular}

به كلاس بيكسل هاى همسايه شده و در نتيجه مىتواند

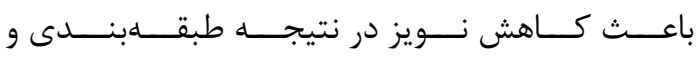

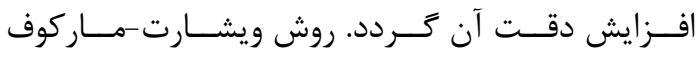

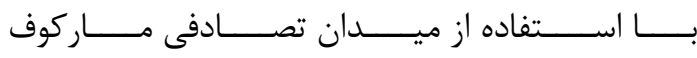

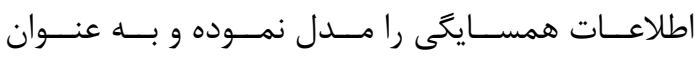
احتمال اوليه كلاسها به روش ويشارت در طبقهبنـدى لهـ

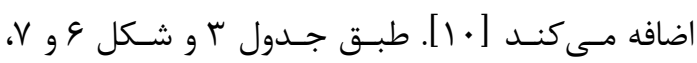

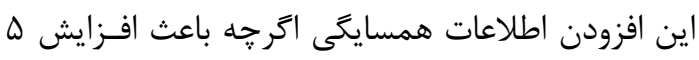

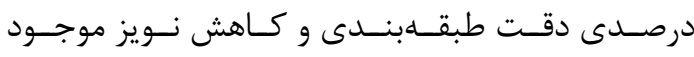
در تصوير حاصل از طبقهبندى شده است امـا همجنــان تفكيك يذيرى خوبى بين كلاسها ايجاد نكرده است.
در ايـن شـكل نيـز مشـاهده مسىشـود كـهـ بسـيارى

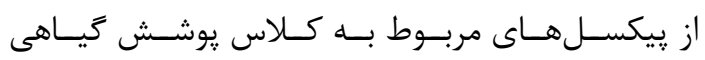

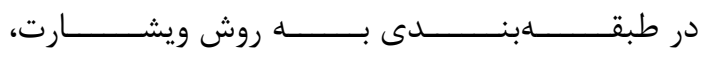
در كلاس گونههاى جنكلى قرار كرفته اسـت و بنـابراين

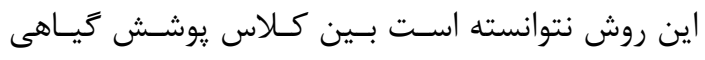

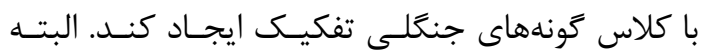

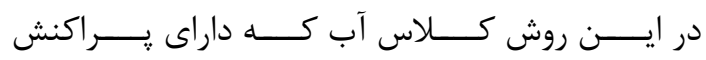

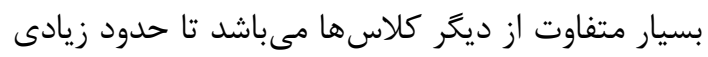
از ديخر كلاسها تشخيص داده شده است به طورى كـهـ

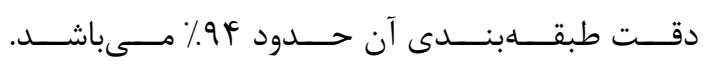

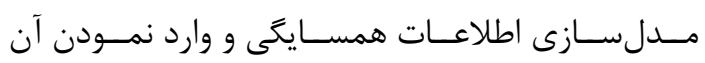

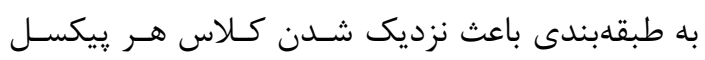




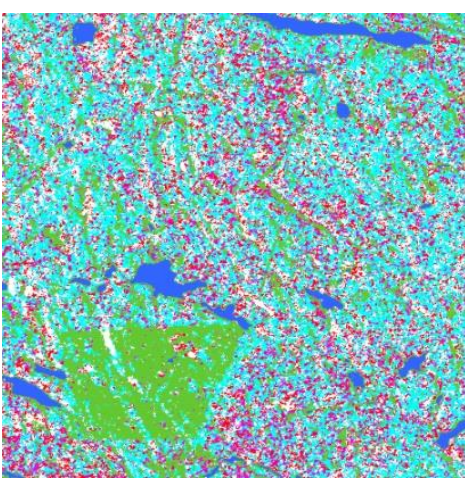

SVM

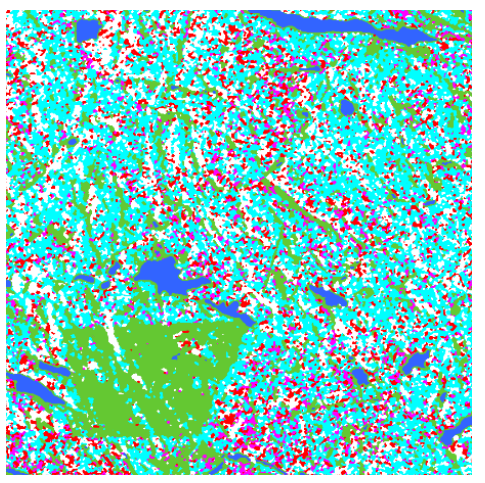

MRF-SVM

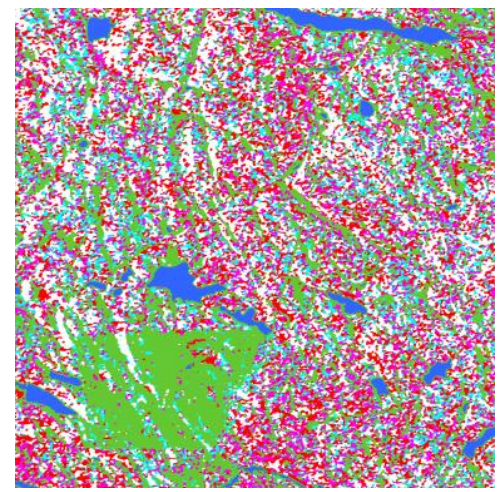

WMRF

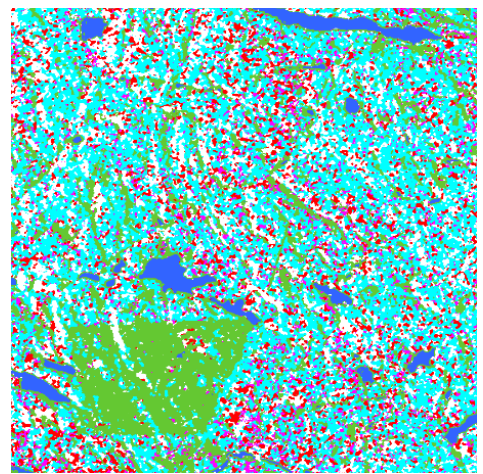

MSVC

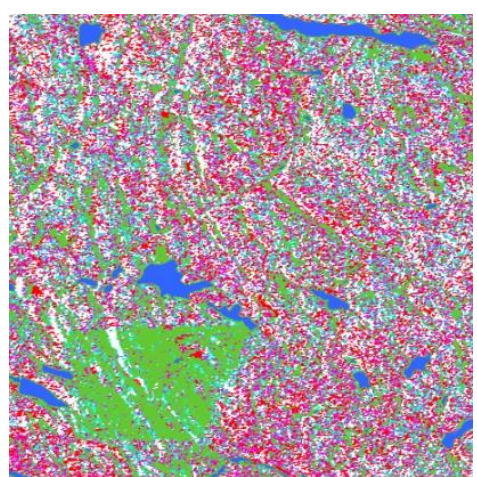

Wishart

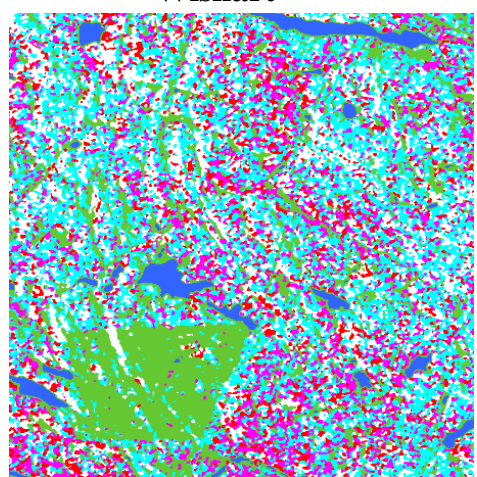

aMRF

\section{Or Po Pr Pw Gv Wa}

شكل \&: نتيجه طبقهبندى به كمك روش هاى مختلف.

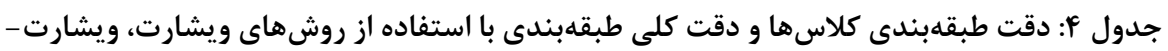

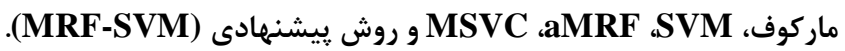

\begin{tabular}{|c|c|c|c|c|c|c|}
\hline Wishart & WMRF & SVM & aMRF & MSVC & $\begin{array}{l}\text { MRF- } \\
\text { SVM }\end{array}$ & كلاس/ روش \\
\hline$r q / r r$ & $r r / 1 \Delta$ & $99 / 1 T$ & $\varepsilon \Delta / I V$ & VA/DH & $11 / 1 T$ & Or \\
\hline$r \Delta / 9 \Lambda$ & $F / / T$ & ५q/l. & $F I / V F$ & $19 / 99$ & $\Delta r / V \mathcal{F}$ & Po \\
\hline$r T / T$. & $r \cdot / T \omega$ & $r \cdot / r \Delta$ & rN/VG & $\mid q / 94$ & $r 1 / 90$ & $\operatorname{Pr}$ \\
\hline r\&/.. & rN/qr & $r \cdot \mid \Lambda T$ & rr/TV & $F Y / Q G$ & $p V / 0 q$ & $\mathrm{Pw}$ \\
\hline$V I / \Delta V$ & $11 / 94$ & $99 / 11$ & 1/RG & VD/Ar & $\Lambda \cdot / \mu$. & Gv \\
\hline$q \mu / v q$ & $q \pi / v q$ & $94 / 9 r$ & $9 F / V \Lambda$ & $94 / 94$ & qp/qu & $\mathrm{Wa}$ \\
\hline $01 / 9 \pi$ & $\Delta \varphi / \Lambda$ & $\Delta 9 / 9 V$ & $\varphi \Delta / \uparrow \varphi$ & $\varepsilon V / \cdot \Delta$ & $V \cdot \mid \Delta f$ & دقت كلى طبقهبندى \\
\hline IV ثانيه IV & ه دقيقه & f دقيقه & ^ دقيقه & F & • ا دقيقه & لزمان اجرا \\
\hline
\end{tabular}

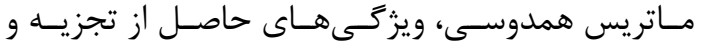
ويزگكىهاى تفكيك كننده SAR نيـز اسـتفاده مسى كنــد.

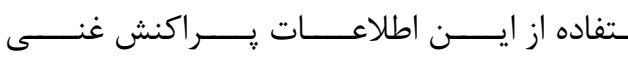

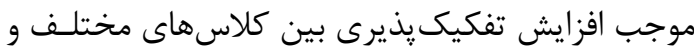

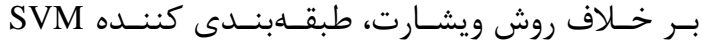

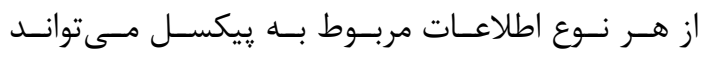

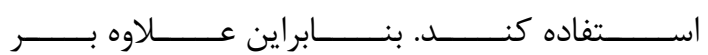

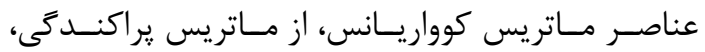


دقت كلى طبقلبندى با كمك روش پيشنههادى نسـبت

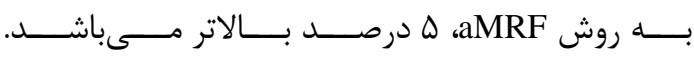
اين در حالى است كه زمان اجـراى آن فقـط دو دقيقـهـ

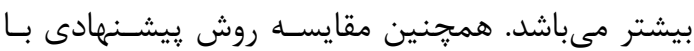

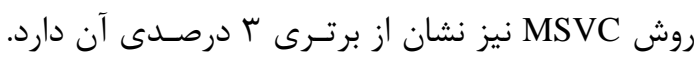

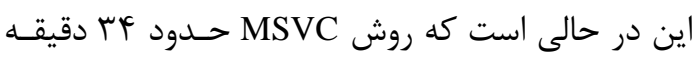

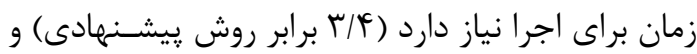

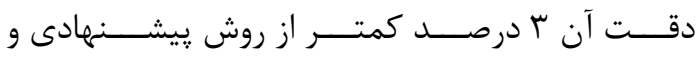
فقط r درصد از روش aMRF بالاتر مىباشد.

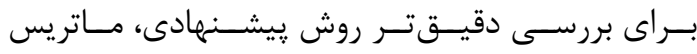

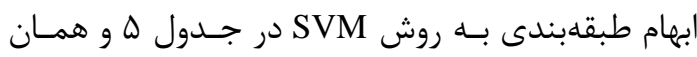

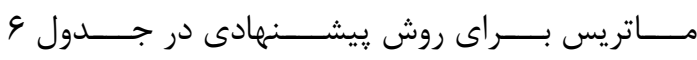

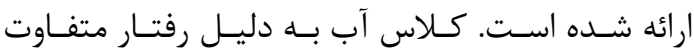

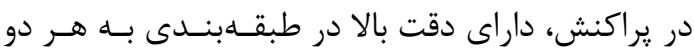

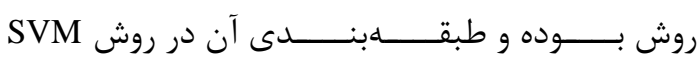
بسيار همكَن بوده بـه طـورى كـهـ اسـتفاده از اطلاعـات

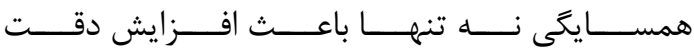

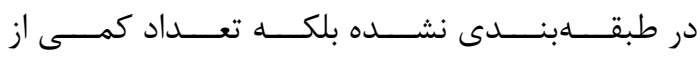

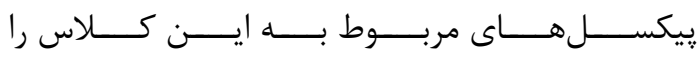

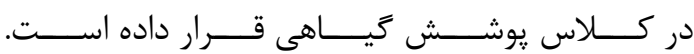

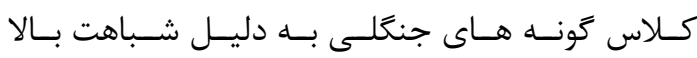

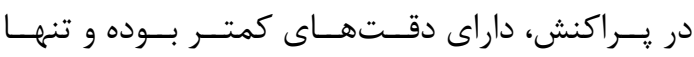

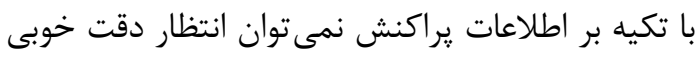

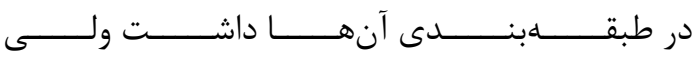

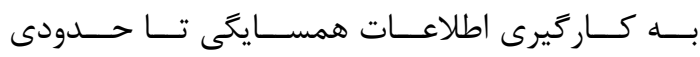
باعث جبران اين شباهت بالا مسى كـردد بــهـ طـورى كـهـ

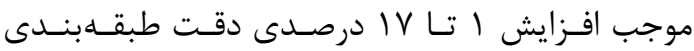

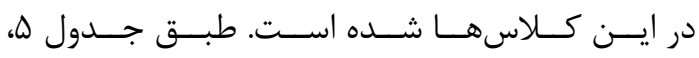

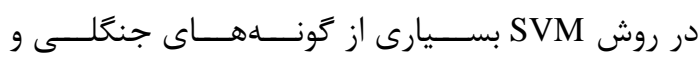
يوشش كياهى در كلاس Or قرار گرفتهاند، در حالى كه

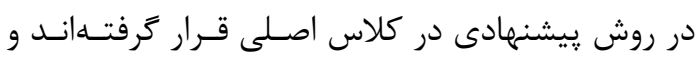
در ضمن بيكسـلهـايى از ايسن كـلاس كـهـ بــهـ اشـتباه

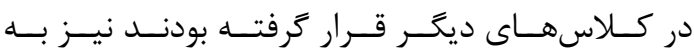

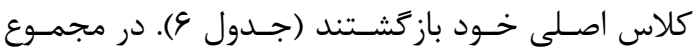

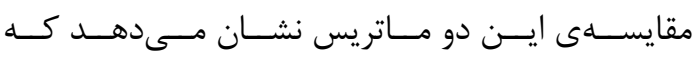

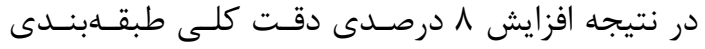

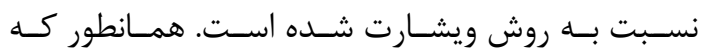
در شكل و و \نيز مشـاهده مسىشـود، تصـوير حاصـل

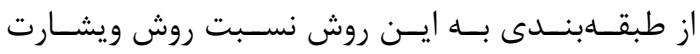

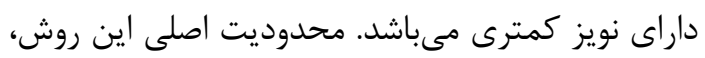

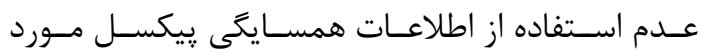
طبقابندى مى باشد. دو روش ديكرى كه در ايـن قسـمت اجـرا شـده اسـت

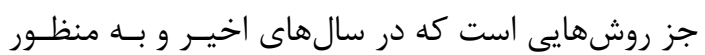

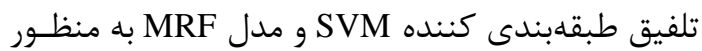

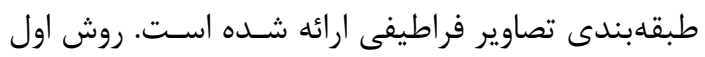

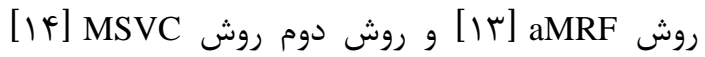

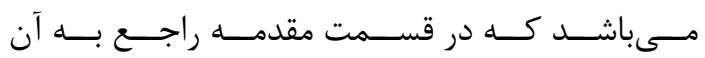

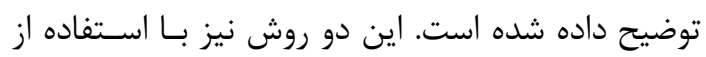

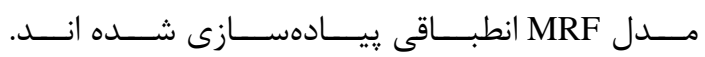

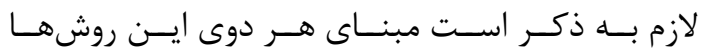
روش SVM بوده و بنابراين همان يارامترهـاى كرنسل و و دون

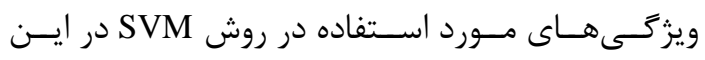

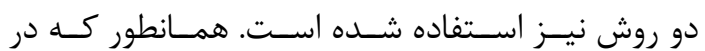

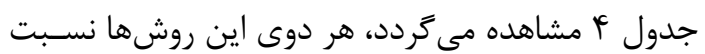

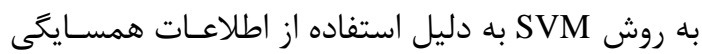

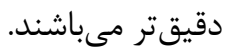
الكَوريتم پِيشنهادى در اين مقاله از اطلاعـات يـراكنش

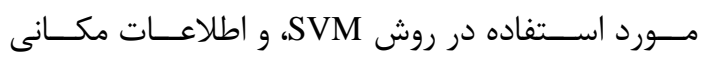

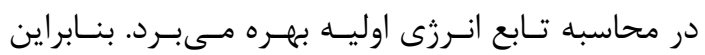

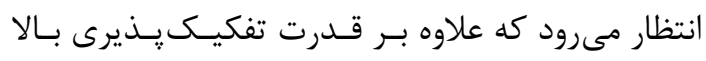

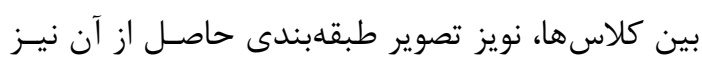

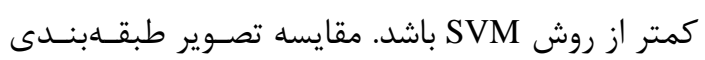

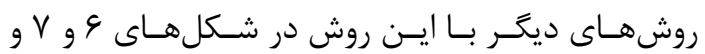

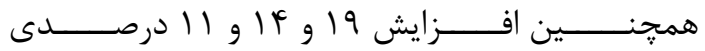
دقت طبقهبندى نسبت به روشهاى به ترتيب وين ويشارت،

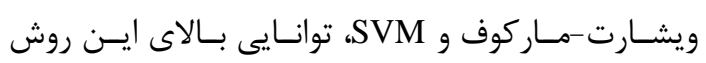
را نشان مى ودهد. 


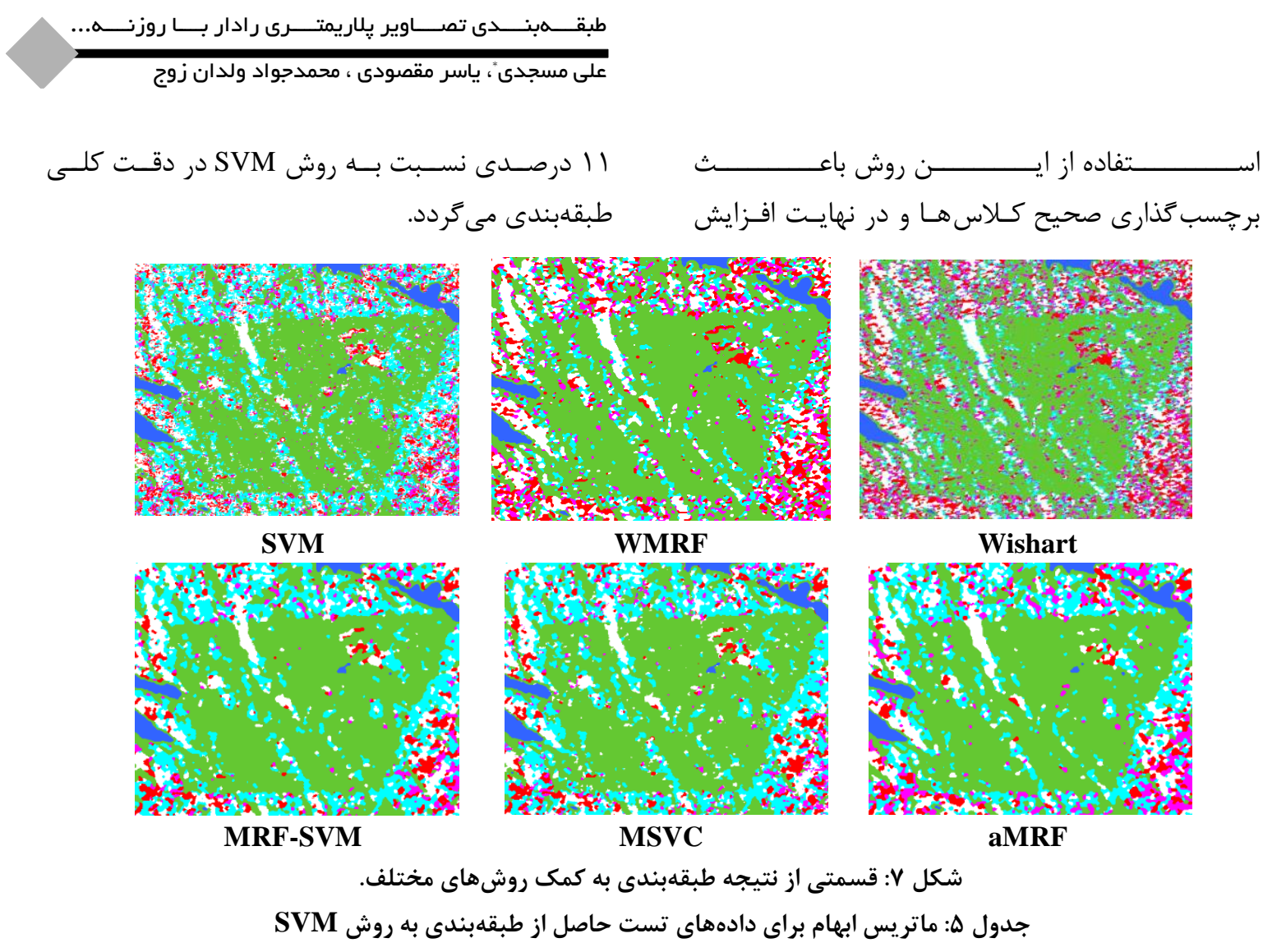

\begin{tabular}{|c|c|c|c|c|c|c|c|}
\hline \multirow[t]{2}{*}{ كلاس درست } & \multicolumn{6}{|c|}{ كلاس طبقهبندى شده } & \multirow[t]{2}{*}{ دقت (./) } \\
\hline & Or & Po & Pr & $\mathrm{Pw}$ & $\mathrm{Gv}$ & $\mathrm{Wa}$ & \\
\hline Or & VEV & 119 & $\Lambda \Lambda$ & $\Lambda$. & 19 & $\cdot$ & $99 / 1 T$ \\
\hline Po & TTV & $r \Delta l$ & TY & $\Delta F$ & $\wedge \varepsilon$ & · & rq/l. \\
\hline $\operatorname{Pr}$ & 149 & $V r$ & 110 & 111 & IT. & • & $r \cdot / \mu \Delta$ \\
\hline $\mathrm{Pw}$ & 149 & $\pi$ & r & IfV & $\Lambda$ & . & $r \cdot \mid \wedge r$ \\
\hline Gv & TMA & ITE & 9 . & 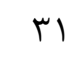 & (111 & re & $99 / 1 /$ \\
\hline $\mathrm{Wa}$ & . & $\Delta$ & $\Delta$ & • & ra & $\varepsilon \Delta F$ & $94 / 94$ \\
\hline
\end{tabular}

\begin{tabular}{|c|c|c|c|c|c|c|c|}
\hline \multirow[t]{2}{*}{ كلاس درست } & \multicolumn{6}{|c|}{ كلاس طبقهبندى شده } & \multirow[t]{2}{*}{ دقت (\%) } \\
\hline & Or & Po & $\operatorname{Pr}$ & $\mathrm{Pw}$ & $\mathrm{Gv}$ & $\mathrm{Wa}$ & \\
\hline Or & 941 & fT & pF & $g y$ & 99 & • & $11 / 1 T$ \\
\hline Po & rוr & THQ & 1 & • & $\Lambda r$ & • & $\Delta r / V{ }^{c}$ \\
\hline $\operatorname{Pr}$ & سوו & fr & ITF & 119 & $11 \mathrm{~V}$ & · & $r 1 / 90$ \\
\hline $\mathrm{Pw}$ & $1 \cdot r$ & $1 \cdot 1$ & iq & rTV & 1 & - & $p V / \Delta q$ \\
\hline Gv & 190 & או & 41 & 19 & $10 \cdot 1$ & rT & $\Lambda \cdot / \mu$. \\
\hline $\mathrm{Wa}$ & • & 1. & . & • & tr & GDT & $q p / q 4$ \\
\hline
\end{tabular}




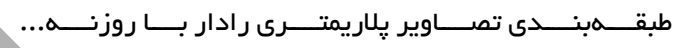

$$
\begin{aligned}
& \text { على مسجدى"، ياسر مقصودى ، محمدجواد ولدان زوج }
\end{aligned}
$$

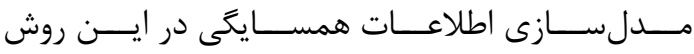

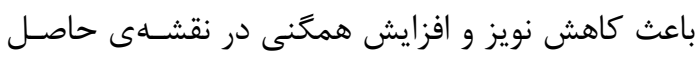

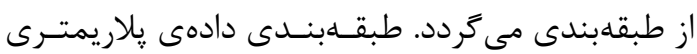

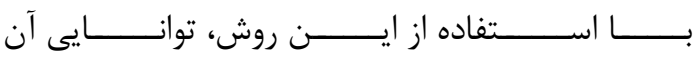

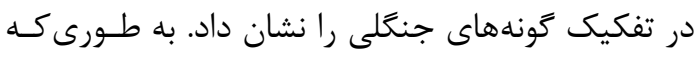

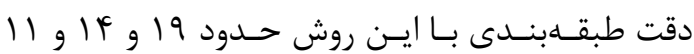

$$
\begin{aligned}
& \text { درصد از دقت طبقهبندى حاصل از روشهاى به ترتيسب } \\
& \text { ويشارت، ويشارت-ماركوف و SVM بيشتر بـوده اسـت دون. }
\end{aligned}
$$

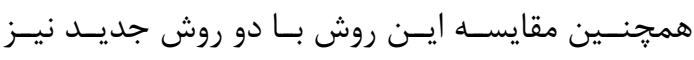

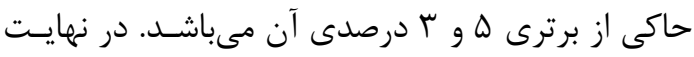

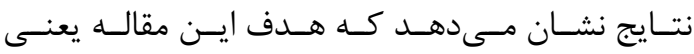

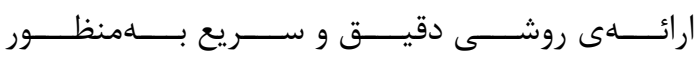

$$
\begin{aligned}
& \text { طبقهبندى دادههاى يلاريمترى محقق گرديده است. }
\end{aligned}
$$

[1] J.S. Lee, M.R. Grunes, and R. Kwok, "Classification of multi-look polarimetric SAR imagery based on complex Wishart distribution," International Journal of Remote Sensing, 15(11), 2299-2311, 1994.

[2] Maghsoudi, Y., "Analysis of Radarsat-2 Full Polarimetric Data for Forest Mapping," Ph.D. dissertation, Calgary University, Calgary, The Canada, 2011.

[3] Alberga, V., "Comparison of polarimetric methods in image classification and SAR interferometry applications," $\mathrm{PhD}$ thesis, Fakultat fiir Elektrotechnik und Informationstechnik der technischen Universitat Chemnitz genehmigte, 2003.

[4] B. E. Boser, I. M. Guyon, and V. N. Vapnik, "A training algorithm for optimal margin classifiers," in Proceedings of the fifth annual workshop on Computational learning theory, pp. 144 -152, 1992.

[5] J. Benediktsson, P. H. Swain, and O. K. Ersoy, "Neural network approaches versus statistical methods in classification of multisource remote sensi ng data," IEEE Transactions on geoscience and remote sensing, vol. 28, pp. 540-552, 1990.

[6] Zhang, B. Zou, J. Zhang and Y. Zhang,

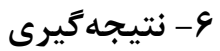

در اين مقالـه طبقـهبنـدى دادههـاى يلاريمتــى SAR

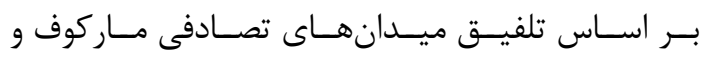

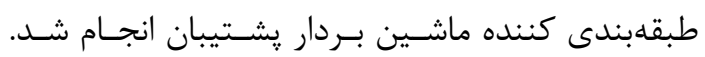

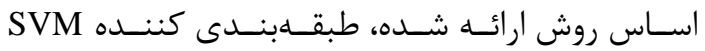

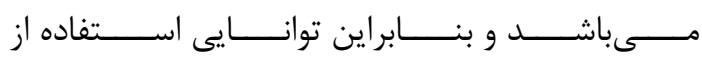

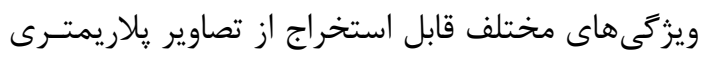

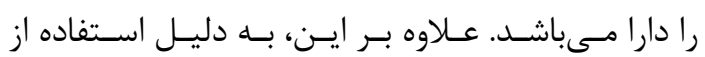

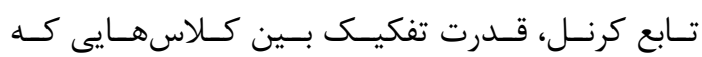

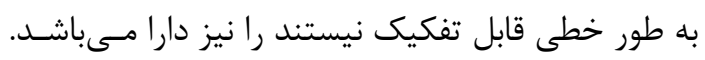

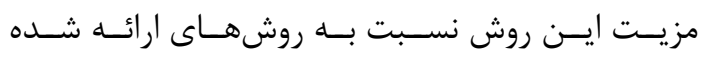

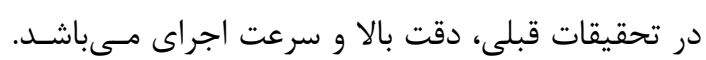

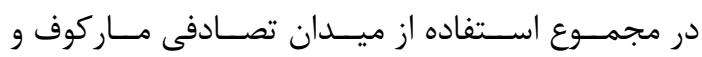

\section{مراجع}

"Classification of polarimetric SAR image based on support vector machine using multiple-component scattering model and texture features," EURASIP Journal on Advances in Signal Processing, vol. 2010, p. $1,2010$.

[7] D. Gleich, "Markov random field models for non-quadratic regularization of complex SAR images," Selected Topics in Applied Earth Observations and Remote Sensing, IEEE Journal of, vol. 5, pp. 952-961, 2012.

[8] Y. Tarabalka, M. Fauvel, J. Chanussot, and J. A. Benediktsson, "SVM-and MRF-based method for accurate classification of hyperspectral images," Geoscience and Remote Sensing Letters, IEEE, vol. 7, pp. 736-740, 2010.

[9] Y. Wu, K. Ji, W. Yu, and Y. Su, "Regionbased classification of polarimetric SAR images using Wishart MRF," Geoscience and Remote Sensing Letters, IEEE, vol. 5, pp. 668-672, 2008.

[10] A. Dargahi, Y. Maghsoudi, and A. Abkar, "Unsupervised Classification of Polarimetric SAR Imagery Using Scattering Mechnism and Markove Random Fields," Journal of Radar, vol. 1, pp. 15-25, 2013. 


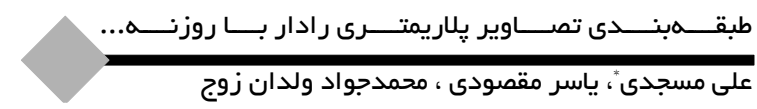

[11] A. Dargahi, Y. Maghsoudi, and A. Abkar, "Supervised Classification of Polarimetric SAR Imagery Using Temporal and Contextual Information," ISPRSInternational Archives of the Photogrammetry, Remote Sensing and Spatial Information Sciences, vol. 1, pp. 107-110, 2013.

[12] Z. Wu, Q. Ouyang, "SVM- and MRF-Based Method for Contextual Classification of Polarimetric SAR Images," Remote Sensing, Environment and Transportation Engineering (RSETE), International Conference on Digital Object Identifier, IEEE, pp. 818 - 821, 2011.

[13] Zhang, B., Li, S., Jia, X., Gao, L., Peng, M. Adaptive Markov random field approach for classification of hyperspectral imagery. Geoscience and Remote Sensing Letters, IEEE 8, pp. 973-977, 2011.

[14] G. Moser, and S. B. Serpico, "Combining Support Vector Machines and Markov Random Fields in an Integrated Framework for Contextual Image Classification," IEEE Trans. Geosci. Remote Sensing, vol. 51, no. 5, pp. 2734-2752, May. 2013.

[15] V. N. Vapnik, Statistical Learning Theory. Hoboken, NJ: Wiley, 1998.

[16] S. Geman and D. Geman, "Stochastic relaxation, Gibbs distributions, and the Bayesian restoration,” IEEE Trans. Pattern Anal. Mach. Intell., vol. PAMI-6, no. 6, pp. 721-741, Nov. 1984.

[17] S. Li, Markov Random Field Modeling in Image Analysis. Berlin, Germany: Springer-
Verlag, 2009.

[18] Q. Jackson and D. Landgrebe, "Adaptive Bayesian contextual classification based on Markov random fields," IEEE Trans. Geosci. Remote Sensing, vol. 40, no. 11, pp. 2454-2463, Nov. 2002.

[19] A. H. S. Solberg, T. Taxt, and A. K. Jain, "A Markov random field model for classification of multisource satellite imagery," IEEE Trans. Geosci. Remote Sens., vol. 34, no. 1, pp. 100-113, Jan. 1996.

[20] T. Zhang, F. Hu, and R. Yang, "Polarimetric SAR image segmentation by an adaptive neighborhood Markov random field," J. Test Meas. Technol., vol. 23, no. 5, pp. 462-465, 2009.

[21] P. Zhong and R. Wang, "Image segmentation based on Markov random fields with adaptive neighborhood systems," Opt. Eng., vol. 45, no. 9, pp. 462-465, 2009.

[22] A. Garzelli, "Classification of polarimetric SAR images using adaptive neighborhood structures," Int. J. Remote Sens., vol. 20, no. 8, pp. 1669-1675, 1999.

[23] X., Niu, Y., Ban, “An Adaptive Contextual SEM Algorithm for Urban Land Cover Mapping Using Multitemporal HighResolution Polarimetric SAR Data", Selected Topics in Applied Earth Observations and Remote Sensing, IEEE Journal of, vol. 5, no. 4, pp. 1129-1139, 2012. 


\title{
Classification of Polarimetric SAR Images Based on Combining Support Vector Machine Classifier and Markov Random Fields
}

\author{
Ali Masjedi*1, Yasser Maghsoudi², Mohamad Javad Valadan Zoej ${ }^{3}$
}

1- M.Sc. student of remote sensing in Department of Geomatics, College of Engineering, K.N. Toosi University

2- Assistant professor in Department of Geomatics, College of Engineering, K.N. Toosi University

3- Associate professor in Department of Geomatics, College of Engineering, K.N. Toosi University

\begin{abstract}
Recent studies show that image classification techniques which use both spectral and spatial information are more suitable, effective, and robust than those that use only spectral information. Although late model support vector machines (SVMs) have been providing accurate results in the studies, this method is intrinsically noncontextual, which represents significant limitation in image classification. In this paper, we propose a rigorous framework which integrates SVMs and Markov random field models in a unique formulation for spatial contextual classification of various species of forest trees, ground vegetation, and water using polar metric synthetic aperture radar data. Genetic algorithm is employed for selecting appropriate features and automatic estimation of optimal parameters. Comparison of the accuracy of the proposed method with baseline methods was performed. Comparison of the accuracy of the proposed method with some other methods was carried out. The results show that this algorithm allowed approximately 19\%, 14\%, 11\%, 5\% and 3\% increase in overall accuracy with respect to the Wishart, WMRF, SVM, aMRF and MSVC methods, respectively.
\end{abstract}

Key words: Markov Random Fields, Support Vector Machine, Contextual Image Classification, Spatial Information.

Correspondence Address Remote Sensing Group, Department of Geomatics, College of Engineering, K.N. Toosi University, Tehran, Iran Tel: +989138669858.

Email: amasjedi@mail.kntu.ac.ir 